\title{
Natural resistance to Fasciola hepatica (Trematoda) in Pseudosuccinea columella snails: A review from literature and insights from comparative "omic" analyses
}

\author{
Alba Annia 1, 2, ${ }^{*}$, Tetreau Guillaume 2, Chaparro Cristian 2, Sánchez Jorge 1, Vázquez Antonio A. 1,3, \\ Gourbal Benjamin 2, *
}

${ }^{1}$ Centro de Investigaciones, Diagnóstico y Referencia, Instituto de Medicina Tropical "Pedro Kouri", La Habana, Cuba

2 University of Perpignan Via Domitia, Interactions Hosts Pathogens Environments UMR 5244, CNRS, IFREMER, Univ. Montpellier, F-66860, Perpignan, France

${ }^{3}$ MIVEGEC, IRD, CNRS, Université de Montpellier, Montpellier, France

* Corresponding authors : Annia Alba, email address : annia.alba@gmail.com ; Benjamin Gourbal, email address : benjamin.gourbal@univ-perp.fr

\begin{abstract}
:
The snail Pseudosuccinea columella is one of the main vectors of the medically-important trematode Fasciola hepatica. In Cuba, the existence of natural $P$. columella populations that are either susceptible or resistant to $F$. hepatica infection offers a unique snail-parasite for study of parasite-host compatibility and immune function in gastropods. Here, we review all previous literature on this system and present new "omic" data that provide a molecular baseline of both $P$. columella phenotypes from naïve snails. Comparison of whole snail transcriptomes (RNAseq) and the proteomes of the albumen gland (2Delectrophoresis, MS) revealed that resistant and susceptible strains differed mainly in an enrichment of particular biological processes/functions and a greater abundance of proteins/transcripts associated with immune defense/stress response in resistant snails. These results indicate a differential allocation of molecular resources to self-maintenance and survival in resistant $P$. columella that may cause enhanced responsiveness to stressors (i.e. F. hepatica infection or tolerance to variations in environmental $\mathrm{pH} /$ total water hardness), possibly as trade-off against reproduction and the ecological cost of resistance previously suggested in resistant populations of $P$. columella.
\end{abstract}

\section{Highlights}

- Comparative "omic" analyses of $P$. columella offer clues for resistance to $F$. hepatica. Naïve resistant snails display a higher molecular competence for defense/stress responses. Constitutively broad expression of immune factors associates with resistance to $F$. hepatica. Overrepresented pH/osmotic regulators endorse the $\mathrm{pH}$ tolerance of resistant snails. Resource allocation to defense/stress response endorse reproductive trade-offs. 
Keywords : transcriptome, albumen gland, allocation of resources, response to stress, immune defense, cost of resistance

\section{Abbreviations}

$\begin{array}{ll}\text { Bge cells } & \text { Biomphalaria glabrata embryonic cell line } \\ \text { G-CSFR } & \text { granulocyte colony stimulatory factor } \\ \text { IRF } & \text { interferon regulatory factors } \\ \text { LBP/BPI } & \text { lipopolysaccharide-binding protein/bactericidal permeability-increasing protein } \\ \text { LRR } & \text { leucine rich repeats } \\ \text { MIF } & \text { macrophage migratory inhibitory factor } \\ \text { Myd88 } & \text { myeloid differentiation primary response } \\ \text { PKC } & \text { protein kinase C } \\ \text { SOD } & \text { superoxide dismutase } \\ \text { TGF } & \text { transforming growth factor } \\ \text { TH } & \text { Total hardness } \\ \text { TLR } & \text { toll-like receptor } \\ \text { TBH } & \text { tyramine } \beta \text {-hydrolase }\end{array}$




\section{Introduction}

Among digenean parasites that are transmitted by snail vectors, those causing fascioliasis (Fasciola spp.) and mainly Fasciola hepatica have gained particular interest due to their wide distribution, their impact on veterinary health and on the economy, in association with livestock infections (Khan et al., 2013, Mehmood et al., 2017), and their re-emergence as human pathogens (Mas-Coma et al., 2009). Fasciola spp. have a two-host life cycle (i.e. mammals and snails as definitive and intermediate hosts, respectively), and transmission in a specific geographical area is mostly dependent on presence of vector snails of the family Lymnaeidae. In this sense, host efficiency may be influenced by the local adaptation between parasite and snail species (Dar et al., 2013, Vázquez et al., 2014).

Worldwide, 30 lymnaeid species are known as intermediate hosts of Fasciola spp. (Vázquez et al., 2018). Particularly, Pseudosuccinea columella (formerly known as Lymnaea columella), considered one of the main intermediate host species for transmission of $F$. hepatica, is an efficient invasive snail species that has attained wide geographical distribution (Lounnas et al., 2017; Vázquez et al., 2018). Presumed to have originated in North America, the high adaptability and invasive capacity of few genotypes have allowed establishment of $P$. columella in several parts of the world (for details, see Lounnas et al. 2017). Nowadays, P. columella is reported in South America and the Caribbean (Cucher et al., 2006, Gutiérrez et al., 2011), as well as in Africa (Brown, 1994), Australia (Molloy and Anderson 2006), several Pacific islands (Cowie 2001, Pointier and Marquet, 1990) and Europe (Pointier et al., 2007).

Concomitantly, the global distribution of this snail species has also complicated the epidemiological scenario of fascioliasis (Lounnas et al. 2017). Transmission of $F$. hepatica by $P$. columella is well documented in and outside of its native range (e.g. Gutiérrez et al. 2011; Cruz-Reyes and Malek, 1987; Cucher et al. 2006) and P. columella snails have been found also naturally infected with Fasciola gigantica (Grabner et al. 2014). Fasciola hepatica infection in this species does reduce snail fecundity (Gutiérrez et al., 2002, Salazar et al., 2006), but is also characterized by higher redial and metacercariae productivity compared to Galba truncatula (Dar et al., 2014, Vignoles et al., 2015) and greater survival when compared to species of Galba (Salazar et al., 2006, Vignoles et al., 2015).

\subsection{Lymnaeid snails and $F$. hepatica transmission in Cuba: resistant and susceptible populations of $P$.} columella

In Cuba, F. hepatica is transmitted by two species of snails: Galba cubensis, considered the main intermediate host, (natural prevalence ranged from 1 to 34\%; Alba et al., 2016, Vázquez et al., 2015) and 
P. columella (Alba et al., under review, Gutiérrez et al., 2011). The latter has a more discrete distribution than G. cubensis (Vázquez et al., 2009); to date reported from only 68 localities in western and central Cuba with no records in the easternmost region of the island (Alba et al., under review). Pseudosuccinea columella shows no preferences for anthropic or natural habitats (Vázquez et al., 2009). Considered to have a secondary role as intermediate host of $F$. hepatica in Cuba (Vázquez et al., 2014), only two populations, located in Pinar del Rio province (i.e. IPA and Pilon, western Cuba), have been found naturally-infected with $F$. hepatica, with prevalence of 3 and 10\%, respectively (Alba et al., under review, Gutiérrez et al., 2011). Despite so relatively few natural infections with $F$. hepatica as compared to $G$. cubensis, snails from most of the $P$. columella field populations can be successfully infected in the laboratory with Cuban F. hepatica isolates (Calienes et al., 2004; Gutiérrez et al., 2002, Vázquez et al., 2014). The prevalence of infection following lab-exposure of $P$. columella to $F$. hepatica varies depending on the snail (population) - parasite (isolate) combination used, indicating the existence of a polymorphism of compatibility in this parasite - host system (Vázquez et al., 2014, Alba et al., 2018).

Remarkably, P. columella snails from particular localities on Cuba, i.e. La Palma, El Azufre, Babiney, La Playita, La Coca and Candelaria (see Alba et al. (under review)) have never been found with naturally occurring $F$. hepatica infection, nor do they incur infection after experimental exposures to field-derived parasites, regardless of the local $F$. hepatica isolates used, challenge with increasing doses of the infective larvae (from 5 to 30 miracidia/snail), through single or serial exposures, and with allopatric parasites from Dominican Republic and from France (Alba et al., 2018, Calienes et al., 2004, Gutiérrez et al., 2002, Gutiérrez et al., 2003b, Vázquez et al., 2014). A previous study informed that the immune cells (hemocytes) of these $P$. columella snails encapsulate $F$. hepatica larva shortly after parasite penetration (at $24 \mathrm{~h}$ post-exposure; Gutiérrez et al., 2003b). The above results indicate the occurrence of an effective immunological response rather than an unsuitability of these snails to F. hepatica (Alba et al., 2018, Gutiérrez et al., 2003b, Vázquez et al., 2014). Interestingly, as with $F$. hepatica-susceptible $P$. columella successful natural and experimental infections of resistant snails with other trematodes occur suggesting a certain specificity of the resistance (authors' unpublished data).

\subsubsection{One species, two phenotypes}

Significantly, resistant and $F$. hepatica-susceptible $P$. columella snails show no differences concerning the anatomy of their reproductive system, and share the same reliable conchological characters that are defined for P. columella: big shell, small spire, large aperture of about two thirds of the shell height and characteristic micro-sculptures in the periostracum (Correa et al., 2011, Pointier, 2008, Vázquez and 
Sánchez, 2015). In addition, amplification and sequencing of nuclear ribosomal genes (1170 bp comprising the $3^{\prime}$ region of the $18 \mathrm{~S}$, ITS-1, 5.8S, ITS-2 and the $5^{\prime}$ region of the $28 \mathrm{~S}$ ) from resistant and susceptible snails showed a slight difference between phenotypes in only two bases, one in each ITS fragment (Gutiérrez et al., 2003a). Such differences represented only $0.17 \%$ of sequence variation between the two strains of $P$. columella and thus, are insufficient to segregate both phenotypes into different species (Gutiérrez et al., 2003a) especially considering the high level of self-fertilization observed in this species (Lounnas et al., 2017). All the above criteria can be used to discriminate certain species of molluscs, even within the family Lymnaeidae (e.g. P. columella; Bargues and Mas-Coma, 1997, Correa et al., 2011) but only when differences are evident. The high similarity encountered between these strains at morphologic, anatomic and genetic levels points at the occurrence of two different phenotypes concerning F. hepatica infection within P. columella species (Gutiérrez et al., 2003a). To our knowledge, this is a unique report of field-occurring resistance/susceptibility in a snail - trematode system with perhaps, the exception of the anti-digenean persistent resistance in the snail isolate BS90 of Biomphalaria glabrata versus Schistosoma mansoni (Paraense and Correa, 1963).

It is important to mention that the inheritance pattern of the specific markers concerning susceptibility and resistance of $P$. columella remains to be established. However, this issue is difficult to resolve by mating experiments as it has been demonstrated, by microsatellite markers-based analysis, that selffertilization constitutes the almost exclusive reproductive strategy of this species, irrespective of its phenotype (Alba et al., under review, Lounnas et al., 2017, Nicot et al., 2008). A high-selfing rate is, in fact, a common feature of the family Lymnaeidae and has been reported also for other species including G. truncatula, the main vector of fasciolosis worldwide (Meunier et al., 2004).

\subsubsection{Morphological and genetic differences between P. columella phenotypes}

The resistant and susceptible $P$. columella populations can be readily and reliably discriminated by a morphological marker consisting of characteristic pigmentation pattern of the mantle (Gutiérrez et al., 2003b). All resistant snails display a band of small sharp spots in the mid-region of the mantle with bigger spots uniformly distributed on the upper and lower sides (Alba et al., under review, Gutiérrez et al., 2003b). Contrastingly, susceptible snails have diffused and sparser mantle spots, scattered without a clearly defined pattern (Gutiérrez et al., 2003b; see Figure 1 for details).

Resistant populations of $P$. columella can be also distinguished from susceptible snails by randomly amplified polymorphic DNA; RAPD (Calienes et al., 2004, Gutiérrez et al., 2003a), mitochondrial 
haplotypes (Lounnas et al., 2017) and nuclear microsatellites (Alba et al., under review; Lounnas et al. 2017). These studies have demonstrated that resistant populations clustered separately from most $P$. columella populations from Cuba (Alba et al., under review, Calienes et al., 2004) and from the rest of the world (Lounnas et al., 2017), supporting the notion of a genetic determinism of the resistance to $F$. hepatica. Such segregation suggests that resistant $P$. columella have been selected from different pools than the susceptible snails that have spread widely, and that $P$. columella snails grouped outside of the "resistant" cluster could be primarily thought as susceptible to F. hepatica. Additionally, resistant populations (i.e: La Palma, El Azufre, Babiney and La Coca), showed higher overall allelic richness and a marked differentiation of microsatellites-based genetic population structure (Alba et al., under review; Lounnas et al. 2017) compared to susceptible $P$. columella from Cuba that were determined to be predominantly monomorphic (Alba et al., under review). These findings point to a more ancient introduction of the resistant populations and a detached evolutionary history from the susceptible phenotype in Cuba (Alba et al., under review). However, despite the indications of an earlier arrival on Cuba, resistant $P$. columella present a very discrete geographical distribution (only six localities listed above) compared to susceptible populations, and this suggest the existence of an ecological cost of the resistance that constraints range expansion in nature (Alba et al., under review).

\subsubsection{Ecological patterns associated to the resistant phenotype: fitness cost of resistance}

A follow-up study on snail abundance conducted in two nearby water bodies harboring either resistant (El Azufre) or susceptible (IPA) P. columella populations showed stable densities for both populations throughout the year. However, abundance of resistant $P$. columella was always lower compared to the susceptible population (Gutiérrez et al., 2005a).

Recently, ecological patterns associated with the distribution of each phenotype in nature have been analyzed separately for resistant and susceptible $P$. columella populations (Alba et al., under review). It was determined that while susceptible and resistant snails share similar ecological requirements, resistant populations only occurred in sites with low richness of other snail species $(3.2 \pm 1.02)$, characterized by slightly acid $(\mathrm{pH}=6-6.5)$ and soft (total hardness $(\mathrm{TH})=4^{\circ}-10^{\circ} \mathrm{d}$ ) water (Alba et al., under review). Experiments in the laboratory showed that lowered $\mathrm{pH} / \mathrm{TH}$ water conditions negatively affect $P$. columella species regardless of the phenotype, but resistant strains were significantly more tolerant to such conditions, as evidenced by higher survival rates, and both greater life expectancy and percentage of viable eggs as compared to susceptible strains (Alba et al., under review). However, lower fecundity rates, delay in egg hatching, late reproductive peaks (Alba et al., under review) and diminished 
net reproductive rate (Gutiérrez et al., 2002) are indistinctively reported in resistant $P$. columella isolates suggesting the occurrence of a certain trade-off against reproduction. Particularly, resistant snails (i.e. La Palma) incur a diminished net reproductive rate if they are reared in the presence of susceptible $P$. columella. By contrast, susceptible snails raised in competition with resistant individuals increase of shell growth and of net reproductive rate (Gutiérrez et al. 2005b). These results have led to the following hypothesis to explain the restricted distribution of resistant $P$. columella in nature. It is postulated that the existence of an ecological cost of the resistance, possibly manifested as reproductive impairments, results in a less competitive potential of resistant compared to susceptible snails (Alba et al., under review). However, the higher tolerance to environmental $\mathrm{pH} / \mathrm{TH}$ stress likely provide the resistant phenotype with an ecological advantage in sites with lower $\mathrm{pH} / \mathrm{TH}$ conditions that are less suitable for other snails, and provide a concomitantly reduced competition from other (species of) snails (Alba et al., under review).

Overall, regarding life traits following experimental challenge with $F$. hepatica, exposed resistant snails exhibited higher survival rates than infected-susceptible isolates (Alba et al., 2018, Gutiérrez et al., 2002). In addition, no significant variations were observed in the fecundity rates between non-exposed and exposed resistant snails (Gutiérrez et al., 2002).

\subsection{Comparative molecular screening identifies differences between resistant and susceptible $P$.} columella

An understanding of the fine mechanisms that mediate $P$. columella resistance to $F$. hepatica is of interest for the development of new strategies aiming at unveiling and controlling $F$. hepatica transmission but also for study of determinants of pathogen virulence and for comparative immunology. However, despite the gathering of extensive phenotypical, genetic and ecological data, no study has been conducted to decipher the molecular scenario that give rise to each distinct $P$. columella phenotype relative to $F$. hepatica. To undertake this task, we sought to investigate differences between naïve susceptible and resistant $P$. columella at both the transcriptome and proteome levels.

Firstly, we constructed a de novo assembled transcriptome for this species from whole snails by RNAseq and performed comparative analysis to identify differential patterns of abundance of transcripts that may possibly account for the phenotypic and ecological features of $P$. columella resistance to $F$. hepatica and tolerance to $\mathrm{pH} / \mathrm{TH}$ stress. Secondly, we performed 2D-electrophoresis, and MS/MS spectrometry, to identify differentially expressed proteins in a particular anatomical compartment of the female snail 
reproductive system, the albumen gland. Apart from its role of producing the perivitelline fluid that is deposed in eggs to nurture the embryos (Duncan, 1975, Geraerts and Joosse, 1984), the albumen gland is also involved in the synthesis of a number of immune effectors and defense proteins (Guillou et al., 2007, Hathaway et al., 2010, Mu et al., 2017, Sen et al., 1992). Therefore, comparative analysis of the proteome of this multifunctional organ can give insights into the suggested trade-off between resistance to $F$. hepatica and reproduction in resistant snail isolates (Gutiérrez et al., 2002, Alba et al., under review).

In this study, we found similar patterns from the transcriptomic and the proteomic approaches: a significant bias towards an overall increased abundance of defense and stress-related process transcripts/proteins was associated with resistant snails versus the $F$. hepatica-susceptible phenotype of $P$. columella. These results support self-maintenance as favored strategy of resistant $P$. columella. Differences in metabolic organization to the detriment of protein synthesis/folding was also observed from both "omic" analyses. This may be particularly significant in the case of the albumen gland, potentially contributing to the reproductive constraints observed in resistant $P$. columella populations. The detected differences in expression are discussed in regard to the differential phenotypic and ecological features of the resistant and susceptible strains. In addition, this paper presents a list of candidate factors for further functional validation as predictors of susceptibility to infection and/or for potential inroads toward control of infection and transmission of fascioliasis by boost snail immune function.

\section{Material and methods}

\subsection{Laboratory-reared P. columella snails}

Five-week-old P. columella snails (average size $5.09 \pm 0.64 \mathrm{~cm}$ ) from F. hepatica-resistant (La Coca) and susceptible (Aurora) populations, reared in the Laboratory of Malacology of the IPK (see Sánchez et al. 1995 for details on rearing) were used for the transcriptomic and the proteomic experiments. To gain an overview on constitutive differences between phenotypes, only naive snails (non-exposed to parasite infection) were sampled.

\subsection{Comparative transcriptomic approach on whole snail}

\subsubsection{RNA extraction and sequencing by Illumina}


Sixty $P$. columella snails per strain were used to obtain three biological replicates of 20 snails each. Briefly, snails were separated from the shell and immediately placed in individual vials containing RNAlater ${ }^{\circledast}$ (Ambion) at a ratio $10 \mu \mathrm{L}$ solution to $1 \mathrm{mg}$ of snail tissue. Samples were kept overnight at $4^{\circ} \mathrm{C}$ and then stored at $-20^{\circ} \mathrm{C}$ until use. For RNA extraction, RNAlater ${ }^{\circledR}$ was discarded and whole-tissues of 20 snails per strain (three biological replicates per strain) were pooled, immediately frozen in liquid nitrogen and homogenized. RNA extraction was performed with TRIzol ${ }^{\circledR}$ Reagent (Ambion) following manufacturer's guidelines. Extracted RNA was purified using RNeasy ${ }^{\circledR}$ Minikit (Qiagen) and treated with DNase following the in-column procedure of Turbo DNA-freeTM kit (Ambion). The quality and quantity of the extracted RNA was assessed on a 2100 Bioanalyzer using an RNA 6000 Nano kit (Agilent Technologies) and by Qubit 2.0 fluorometry (Invitrogen).

One $\mu \mathrm{g}$ of total RNA from each biological replicate was used for library preparation using Illumina TruSeq stranded mRNA kit and RNA sequencing was performed by Fasteris SA (Geneva, Switzerland), collecting paired-end, 75-bp read length reads, with three samples multiplexed per lane, using the Illumina HiSeq ${ }^{\mathrm{TM}} 4000$ platform.

\subsubsection{De novo assembly and annotation of $P$. columella transcriptome}

A de novo transcriptome of $P$. columella was assembled using high-quality reads (quality $>38$ phred score) from all six sequenced samples using the default options (which includes the normalization step) of Trinity 2.0.6.1 method (Grabher et al., 2011) on Galaxy Project Server (Giardine et al., 2005) at the instances of the IHPE laboratory (http://bioinfo.univ-perp.fr). From a total of 592 million raw reads, the first consensus transcriptome for $P$. columella resulted into 158837 contigs, named full-transcriptome. To reduce its complexity, Trinity Super Assembly (Grabher et al., 2011) was applied to the de novo assembled transcriptome, and all transcripts shorter than 300 bp were removed, with 78774 transcripts remaining for further analysis. Afterwards, as two phenotypes (and populations) with genetic differences within P. columella were included for RNAseq (see Alba et al., under review; Calienes et al., 2004; Lounnas et al., 2017), hypervariable families were reduced by CD-Hit-est (Li and Godzik, 2006) by clustering transcripts with matches above 95\% identity. This results in 72748 transcripts, designated by the name simplified transcriptome. We used BUSCO tool (available http://busco.ezlab.org/v1; Simão et al. 2015) to assess the quality and completeness of the assembled transcriptomes. We obtained 909 out of 978 complete BUSCOs; no information losses resulted from the reduction steps. All RNAseq data is available in the Sequence Read Archive of NCBI under the following accession numbers: Submission 
number SUB5947916; BioProject: PRJNA555222: Pseudosuccinea columella RNA sequencing; BioSample: SAMN12305757: Pseudosuccinea columella RNAseq (TaxID: 31228). Transcriptomes are also available at the laboratory database: http://ihpe.univ-perp.fr/acces-aux-donnees/.

The automatic annotation of the simplified transcriptome was performed by Blast2GO version 2.4.2 (Conesa et al., 2005) using BLASTx against the National Center for Biotechnology Information (NCBI) non-redundant ( $\mathrm{nr}$ ) sequences database (with an E-value threshold set at $1 \mathrm{E}-03$ ) was performed. Gene function, protein domain and enzyme annotation were also assigned by similarity searches using the Gene Ontology (GO) database and InterPro scan. Annotation results were obtained for only 38968 transcripts (49.5\%).

\subsubsection{Comparative analysis between resistant and susceptible P. columella}

For comparative analysis between susceptible and resistant $P$. columella phenotypes, quality reads (phred score > 38) were aligned to the reduced assembled transcriptome using Bowtie2 v 2.0.2 (Langmead and Salzberg, 2012) set in fast end-to-end mode. Transcripts were counted with Salmon (Patro et al., 2017) and differential expression was calculated by DESeq2 (Love et al., 2014), accounting for over or under-representation in the resistant phenotype. As threshold criteria, only differentiallyexpressed transcripts with adjusted $P<0.05$ and displaying more than 2 -fold changes were considered. All RNAseq analyses were run locally using the Galaxy Project server (Giardine et al., 2005).

Enrichment analyses of the transcriptome involving biological processes or molecular functions, considering separately over- and under-expressed transcript data, were performed using Fisher's Exact Test run on Blast2GO software. A particular GO term with $P$ and false discovery rate (FDR) $<0.05$ was considered enriched. In addition, differentially-expressed transcripts were evaluated combining Gene Ontology (GO) terms and keyword list of well-known defense molecules to select the genes putatively involved in immunity (i.e. defense response, wound healing and inflammation) and in relation to acidbase balance (i.e. carbon-bicarbonate buffering and ion transportation).

\subsection{Comparative proteomic approach on the albumen gland}

\subsubsection{Protein extraction of albumen glands}

The albumen gland of 15 naive snails from each strain (biological replicates) was removed by dissection, lyophilized and individually processed. Briefly, the crude extract of the albumen gland from each 
individual snail was obtained by sonication on ice at $20 \%$ amplitude (Vibra Cell 75185 sonicator; Bioblock Scientific) for $20 \mathrm{~s}$ in $80 \mu \mathrm{L}$ of ice-cold denaturing buffer (urea $7 \mathrm{M}$, thiourea $2 \mathrm{M}, \mathrm{CHAPS} 4 \%$ in Tris- $\mathrm{HCl}$ $30 \mathrm{mM}, \mathrm{pH} 8.5$ ) and clarified by centrifugation at $2000 \times \mathrm{g}, 15 \mathrm{~min}, 4^{\circ} \mathrm{C}$. Protein concentration of the supernatant was estimated using the 2D Quant Kit (GE Healthcare) and samples were stored at $-80^{\circ} \mathrm{C}$ until used.

\subsubsection{D gel electrophoresis of protein extracts from $P$. columella albumen glands}

Proteins extracted from each albumen gland were individually analyzed by 2D gel electrophoresis (15 gels per strain, each corresponding to different biological replicates). One-hundred $\mu g$ of proteins from each extract were added to rehydration buffer (urea $7 \mathrm{M}$, thiourea $2 \mathrm{M}$, CHAPS 4\%, DTT $65 \mathrm{mM}$ ) for a total volume of $350 \mu \mathrm{L}$. Individual samples were loaded onto $17 \mathrm{~cm}$ isoelectric focusing strips (BioRad) with a stabilized non-linear $\mathrm{pH}$ ranging from 3 to 10. Passive strip rehydration was achieved by $5 \mathrm{~h}$ at $22^{\circ} \mathrm{C}$, followed by an active rehydration of $14 \mathrm{~h}$ under a $50 \mathrm{~V}$ current (to help big proteins to enter into the strips) at the same temperature. Afterwards, isoelectric focusing of proteins was performed using the following program: $50 \mathrm{~V}$ for $1 \mathrm{~h}, 250 \mathrm{~V}$ for $1 \mathrm{~h}, 8,000 \mathrm{~V}$ for $1 \mathrm{~h}$ and a final step at 8,000 $\mathrm{V}$ for a total of $90,000 \mathrm{Vh}$ with a slow ramping voltage (quadratic increasing voltage) at each step. Focused proteins were reduced by incubating the strip twice with equilibration buffer (Tris, $1.5 \mathrm{M}$; urea, $6 \mathrm{M}$; SDS, 2\%; glycerol, 30\%; bromophenol blue; $\mathrm{pH} 8.8)$ containing DTT (130 mM) at $55^{\circ} \mathrm{C}$. Then, proteins were alkylated by an incubation with equilibration buffer containing iodoacetamide (135 $\mathrm{mM}$ ) on a rocking agitator $(400 \mathrm{rpm})$ at room temperature protected from light. Proteins were separated according to their molecular weight (second dimension) on 12\% acrylamide/0.32\% piperazine diacrylamide gels run at $25 \mathrm{~mA}$ /gel for $30 \mathrm{~min}$ followed by $75 \mathrm{~mA} /$ gel for $8 \mathrm{~h}$ using a Protean II XL system (Bio-Rad). Gels were stained with MS-compatible silver staining protocol and scanned using a ChemiDoc MP Imaging System (Bio-Rad) associated with Image Lab software version 4.0.1 (Bio-Rad).

\subsubsection{Comparative analysis of $2 D$-gels between susceptible and resistant $P$. columella}

Considering the complexity of the 2D gel profile of albumen gland, and quality of sample resolution, five most representative gels per strain were selected for comparative analysis on PD-Quest v. 7.4.0 (BioRad) to identify differences in protein abundance between proteomic profiles of albumen glands from susceptible versus resistant individual snails. When a spot was reproducibly present in all five replicates from one strain and absent from all five replicates from the other strain, it was considered a qualitative change. For quantitative changes, only spots whose mean intensity across five replicates per strain was 
304

305

306

307

308

309

310

311

312

313

314

315

316

317

318

319

320

321

322

323

324

325

326

327

328

329

330

331

332

333

four-fold higher or lower than those from the other strain, with a $P<0.01$ (Mann-Whitney U-test), were considered as significantly differentially abundant between the two strains. Selection of spots for further analysis by MS/MS spectrometry was based on qualitative (i.e. present in only one of two phenotypes) or highly quantitative differences (i.e. $>4$-fold differentially abundant; $P<0.01$ ). Differentially represented spots were excised from the gels, destained, trypsin digested and the obtained peptides were identified by tandem mass spectrometry using the PISSARO platform facility (University of Rouen, France).

For the identification of the protein(s) present in each spot, the obtained peptides were matched to the consensus de novo assembled full transcriptome for $P$. columella (158837 transcripts). The transcript sequences confidently matching the peptides were used as a query for a XBLAST against non-redundant NCBI database to determine the protein identity of the best match. Up to the first three best hits were considered, when at least 4 peptides matched the sequence with a coverage $>10 \%$. Identified transcripts sequences were translated into protein using Expasy server (Gasteiger et al., 2013) to identify conserved domains with CDD (Marchler-Bauer et al., 2015). The theoretical pl and molecular weight were also calculated using the Expasy server (Gasteiger et al., 2013) to cross-reference the protein sequence data with the location of the spot on the gel. Altogether, these complementary analyses allowed confident characterization of the protein identity of each spot.

\section{Results}

\subsection{Transcriptomic differences between susceptible and resistant $P$. columella phenotypes}

Overall, $97.49 \%$ of the Illumina RNAseq reads from both phenotypes of $P$ columella were successfully realigned against the simplified transcriptome. A total of 6876 transcripts (9.45\%; 4126 up-regulated and 2750 down-regulated) showed a significantly greater than 2 -fold differential-expression between phenotypes (see supplementary data 1) from which 3290 transcripts (47.5\%) had no annotation results.

Results from the enrichment analyses for both over- and under-represented transcripts (test data) relative to the annotated simplified transcriptome (reference data) are shown in Figure 2 and supplementary data 2 . Analysis of the increased expression transcript data set showed that the resistant phenotype associated with five main categories of biological processes: biological regulation and homeostasis, defense/stress responses, primary signaling pathways/transduction, and nitrogen metabolism, particularly biosynthesis, maintenance and repair of DNA (Figure 2A). In addition, molecular functions related to signal transduction (e.g. transmembrane receptor/G-protein coupled receptor and 
protein tyrosine phosphatase activities) and with $\mathrm{Ca}^{2+}$ binding were enriched in the resistant isolate (Figure 2B). Contrastingly, metabolic process that were related to protein synthesis were underrepresented in resistant snails (e.g. ribosome biogenesis, structural constituent of ribosome, peptide biosynthetic process, translation; Figure $2 \mathrm{C}$ ).

It was particularly significant to find an enrichment in biological processes related to defense and stress response in the resistant phenotype (see Figure 2A) supported by increased abundance in resistant snails of transcripts for pathogen receptor/interacting molecules, transcripts with regulatory roles in immunity and molecules involved in the activation and orchestration of defense responses (see Figure 3 A, B; supplementary data 1). These included several lectins, CD109, cytokines and cytokine-related molecules (e.g. macrophage migration inhibitory factor (MIF), granulocyte colony stimulatory factor receptor (G-CSFR), transforming growth factor 1-beta (TGF1 $\beta)$ ), as well as of signaling/regulatory transcripts (e.g. Toll-like receptors (TLR), protein C kinase (PKC) members of the superfamily of tumoral necrosis factor (TNF) receptors and interferon regulatory factors (IRF), see (Figure 3B).

Additionally, potential anti-parasitic defenses like ferritin, nitric oxide synthase and antioxidant molecules such as catalase, superoxide dismutase (SOD) and probable deferrochelatase peroxidase were also more abundant in resistant snails (Figure 3B). Increased levels of immune surveillance in the resistant phenotype were suggested by transcripts that can function in leukocyte adhesion, rolling and tethering (interference hedgehog-like, Ras-like GTP-binding Rho1, rho-associated kinase 1), and wound healing (Ras-like GTP-binding Rho1).

Concordant with the association of greater tolerance for variations in $\mathrm{pH}$ and $\mathrm{TH}$ levels with snails from resistant $P$. columella populations (Alba et al., under review), several major ion regulatory factors, and other transporters that contribute to $\mathrm{pH}$ and osmotic regulation were observed more from resistant snails (Figure 3C; supplementary data 1). In addition, carbonic anhydrase transcripts were also found highly abundant in this isolate (Figure 3 C).

\subsection{Qualitative and quantitative differences between proteomes of albumen glands from susceptible} and resistant $\mathrm{P}$. columella phenotypes

Albumen glands of $P$. columella exhibited complex proteomic profiles notably consisting of highly abundant proteins of high molecular weight and acidic pl (upper left part of the gels in Figure 4). Such highly abundant proteins with several isoforms can mask nearby proteins and impede the quantitative analysis and proper protein identification. Therefore, this region of the gels, identified with a white 
rectangle in Figure 4, was excluded from analysis. A total of 554 spots were identified from both proteomes, from which more than $80 \%$ were present and similarly abundant in both phenotypes.

However, 18 spots were uniquely to resistant snails while 13 were only observed from susceptible individuals (supplementary data 3; Figure 4). Twenty-eight spots differed significantly $(P<0.01$, MannWhitney U-test, $>4$-fold) in abundance between resistant and susceptible $P$. columella (Supplementary data 3; Figure 4), 12 and 16 spots of the resistant strain were over- and under-represented, respectively compared to the susceptible strain (Supplementary data 3; Figure 4). The ratios of resistant/susceptible quantity ranged from 0.24 (spot \# 2107) up to 26.11 (spot \# 7117).

The selection of 59 spots representing differentially expressed proteins for MS characterization yielded successful identification of 49 proteins and several isoforms (Table 1; Supplementary data 3). No identification was made from spots 7107,7108 and 6515 . Spot 6002 contained two protein isoforms with $67 \%$ sequence similarity (E-value $=2 \mathrm{E}-67$ in BLASTp output; Supplementary data 3 ) to an uncharacterized protein (LOC106073623) predicted from genome sequence of B. glabrata snails (NCBI Biomphalaria glabrata Annotation Release 100), which has been associated with certain lysozyme and peptidoglycan binding activities according to BLASTp consensus (Buddenborg et al. 2017). However, no putative conserved domains were detected in the isoforms of spot 6002 (Supplementary data 3). The presence of more than one protein or of different protein isoforms into the same spot in the same gel was expected due to the complexity of the electrophoretic profiles (see Figure 4).

Table 1 summarizes the proteins (from one up to four hits per spot) that were identified by MS analysis from the 59 spots excised from the 2D gels. Overall, defense/stress and metabolism-related molecules were more abundant in resistant snails (Table 1). Particularly, G-type lysozyme and lipopolysaccharidebinding protein/bactericidal permeability-increasing protein (LBP/BPI) were only observed in resistant snails (Table 1). Conversely, proteins related to protein anabolism were underrepresented in resistant compared to susceptible snails (Table 1). It is worth noting some qualitative differences between isolates that concern the proteins that were identified as involved in signaling processes. In this sense, abundance of tyramine $\beta$-hydrolase like (TBH) in resistant snails, an enzyme that catalyzes the conversion of the neurotransmitter tyramine into octopamine, contrasts with the lower representation of dopamine $\beta$-hydrolase-like monooxygenase (which mainly converts dopamine in norepinephrine) as compared with susceptible snails (Table 1). 
Table 1. Characterization by 2D electrophoresis/Mass Spectrometry of components that differ qualitatively (underlined spot \#) or quantitatively between proteomic profiles of albumen gland from resistant and susceptible Pseudosuccinea columella strains.

\begin{tabular}{|c|c|c|c|}
\hline \multirow{2}{*}{$\begin{array}{l}\text { Primary } \\
\text { Function }\end{array}$} & \multirow{2}{*}{ Protein Annotation } & \multicolumn{2}{|c|}{ Present/abundant (spot \#) } \\
\hline & & Susceptible & Resistant \\
\hline \multirow{9}{*}{$\begin{array}{l}\text { Defense / } \\
\text { stress }\end{array}$} & G-type lysozyme & - & $\underline{6118} ; 7117$ \\
\hline & Glutathione S-transferase & 2107 & - \\
\hline & L-amino acid oxidase -like & $\begin{array}{c}2005 ; 5004 ; \\
8301 ; 8305 ; 7203\end{array}$ & $\begin{array}{l}3615 ; 4826 ; \\
4824 ; 5709\end{array}$ \\
\hline & $\begin{array}{l}\text { Lipopolysaccharide-binding protein/bactericidal } \\
\text { permeability-increasing protein (LBP/BPI) }\end{array}$ & & $\underline{3615}$ \\
\hline & Pathogenesis related protein 1 like & & 8011 \\
\hline & Pathogenesis related protein 1-3 like & 7001 & - \\
\hline & Programed cell death protein 6-like isoform $\mathrm{X} 2$ & 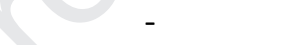 & 108 \\
\hline & Protein disulfide isomerase A3-like & - & 5709 \\
\hline & Protein disulfide isomerase A6 & - & $\underline{3615}$ \\
\hline \multirow{5}{*}{$\begin{array}{l}\text { Matrix / } \\
\text { adhesion }\end{array}$} & Cartilage matrix protein-like & $\underline{7114}$ & - \\
\hline & Dermatopontin 2 & $\underline{1025}$ & - \\
\hline & Filaggrin-like/ cartilage acidic protein 1-like & $\frac{4503}{1001 ;} ; \frac{1025}{1114}$ & $\frac{5208 ; 7117 ;}{1409 ; 8011}$ \\
\hline & Matrilin/Cartilage matrix protein & 6119 & - \\
\hline & TGF- $\beta$-induced protein ig-h3 & $\frac{3005}{8301 ; 2107 ;} 8305$ & $\underline{4306} ; 1409$ \\
\hline \multirow{9}{*}{$\begin{array}{l}\text { Metabolism } \\
\text { and acid- } \\
\text { base balance }\end{array}$} & $\begin{array}{l}\text { 3-oxoacyl - [acyl carrier protein] reductase FabG- } \\
\text { like }\end{array}$ & - & 9303 \\
\hline & 4-hydroxyphenylpyruvate dioxygenase-like & - & 5509 \\
\hline & Adenylate kinase 2 mitochondrial-like & 7203 & - \\
\hline & Arginine kinase & - & 5509 \\
\hline & $\begin{array}{l}\text { Bifunctional purine biosynthesis protein PURH- } \\
\text { like }\end{array}$ & $6818 ; 5808 ; 5713$ & - \\
\hline & Carbonic anhydrase 7-like & - & $\underline{4306}$ \\
\hline & $\begin{array}{l}\text { Cytochrome b-c1 complex subunit } 2 \\
\text { mitochondrial-like }\end{array}$ & - & 8608 \\
\hline & Citrate synthase mitochondrial like & $\underline{6602}$ & $\underline{5618}$ \\
\hline & Purine nucleoside phosphorylase-like & - & $\overline{4306}$ \\
\hline \multirow{8}{*}{$\begin{array}{l}\text { Protein } \\
\text { synthesis / } \\
\text { assembly / } \\
\text { folding }\end{array}$} & $40 \mathrm{~S}$ ribosomal protein $\mathrm{S} 2$ & $8301 ; 8305$ & - \\
\hline & 40 S ribosomal protein S7-like & $\underline{6110}$ & - \\
\hline & $40 S$ ribosomal protein S12-like & $\overline{2005}$ & - \\
\hline & $60 S$ ribosomal protein L7a-like & $8301 ; 8305$ & - \\
\hline & $60 \mathrm{~S}$ acidic ribosomal protein PO-like & - & 9303 \\
\hline & Elongation factor 1-gamma like & $\underline{6602}$ & $\underline{5618}$ \\
\hline & Peptidyl-prolyl-cis-trans isomerase 5-like & $\overline{1114}$ & - \\
\hline & Peptidyl-prolyl-cis-trans isomerase B-like & $\underline{8108} ; \underline{8106}$ & $\underline{9203} ; \underline{9204}$ \\
\hline $\begin{array}{l}\text { Protease and } \\
\text { protease }\end{array}$ & $\begin{array}{l}\text { Serine peptidase } 2 \text { / fibrinolytic enzyme, isozyme } \\
\text { C-like }\end{array}$ & 3210 & $\underline{4210}$ \\
\hline
\end{tabular}


inhibitors

Serpin B-like protein 2

5005; 3214;

Serpin B3-like

-

5106

6602

$\underline{5618}$

4503; 7114;

2011; 2005;

Serpin Z2B-like

1114; 6818;

108; 1409; 4601

2107; 6119;

5808; 5713

\begin{tabular}{|c|c|c|c|}
\hline \multirow{6}{*}{$\begin{array}{l}\text { Signaling } \\
\text { process and } \\
\text { transduction }\end{array}$} & $\begin{array}{l}\text { Dopamine } \beta \text {-hydrolase (DBH)-like } \\
\text { monooxygenase protein } 1\end{array}$ & $6818 ; 5808 ; 5713$ & - \\
\hline & Guanylate kinase like & - & $\underline{9203}$ \\
\hline & & $4102 ; \underline{7009}$, & \\
\hline & Neurogenic locus Notch protein & $\underline{7001} ; \underline{6110} ;$ & $\underline{2112} ; 108$ \\
\hline & & $\overline{4111} ; \overline{2107}$ & \\
\hline & Tyramine-beta hydroxylase like & - & $4824 ; 4826$ \\
\hline \multirow{9}{*}{$\begin{array}{l}\text { Other } \\
\text { functions }\end{array}$} & Endo-beta-1,4 glucanase & $\underline{7009} ; 8305$ & - \\
\hline & $\begin{array}{l}\text { Glutamyl tRNA (GIn) amidotransfer } \\
\text { mitochondrial like }\end{array}$ & - 10 & 1409 \\
\hline & Hemocyanin-like & $5808 ; 5713$ & - \\
\hline & Histone $\mathrm{H} 4$ & - & 4117 \\
\hline & Lamin B1-like & - & $\overline{4826}$ \\
\hline & Probable ATP-dependent RNA helicase DDX 43 & 3210 & - \\
\hline & Ribonuclease UK-144-like & 3002 & $\underline{4006}$ \\
\hline & Protein DGCR14-like & 7203 & $\overline{-}$ \\
\hline & WD repeat-containing protein 36 -like & $\underline{2011}$ & - \\
\hline
\end{tabular}

\section{Discussion}

4.1. Omics provide a molecular baseline for phenotypic and ecological features of $P$. columella snails that are naturally resistant to $F$. hepatica

\subsubsection{Molecular clues for parasite resistance and high tolerance to $\mathrm{pH} / \mathrm{TH}$ variations}

400

401

402

403

404

405

406

407

408

Resistance to $F$. hepatica in $P$. columella has been associated with an active encapsulation of the invading parasite shortly after penetration that develops fully within $24 \mathrm{~h}$ post-exposure and that eventually leads to the death of the larvae and to the resolution of the infection (Gutiérrez et al., 2003b). The consistent nature of the rapid commitment to this immune response in resistant $P$. columella, and the lack thereof in snails from susceptible populations reasonably support the thought that some features involved in the susceptibility/resistance to the parasite $F$. hepatica are constitutively evident in each snail phenotype. In the present paper, both mRNA- and protein-centered "omic" approaches showed an overall enrichment in resistant snails, of biological functions associated with defense and stress responses. It is worth to mention that proteomic differences could be more 
extensive, due the exclusion of the top left region of gels (lots of large proteins) from the study. However, these finding are possibly related to the fact that both defense and stress responses are linked by several molecular functions, effectors and signalling pathways (Demas et al., 2011, Matozzo et al., 2012). In fact, both the effective hemocytic encapsulation of $F$. hepatica (Gutiérrez et al., 2003b) and the higher tolerance to $\mathrm{pH} / \mathrm{TH}$ variations associated with resistant $P$. columella (Alba et al., under review) are responses toward (biotic or abiotic) stressors.

On the one hand, the greater abundance of immune-related transcripts/proteins (e.g. several lectins, pro-inflammatory signaling pathways, cytokines, effector molecules) compared to susceptible snails, may provide significant advantage to resistant snails, enabling the accelerated mounting and regulating of an early and efficient immune response to F. hepatica. Similarly, elevated constitutive molecular processes were proposed to be the base for snail refractoriness to parasite immunosuppressive factors in B. glabrata strains, experimentally-selected for resistance to Echinostoma caproni (Humbert and Coustau, 2001). Notably, representation of plasma proteins differed significantly in these susceptible and resistant $B$. glabrata strains and was linked to a differential gene regulation expressed in the albumen gland (Vergote et al., 2005).

On the other hand, overall higher abundance in resistant snails of several carbonic anhydrase isoforms, both at the transcriptomic or the proteomic level (see Figure 3C, Table 1) suggests a higher potential to compensate for $\mathrm{pH}$ variations (Freitas et al., 2006). Likewise, given that water acidification negatively affects osmotic regulation in aquatic invertebrates (Freitas et al., 2006, Mattews, 2017), constitutive over-representation of different ion regulators and transporters (see Figure $3 \mathrm{C}$ ) may, in part, provide the molecular bases the for increased tolerance to $\mathrm{pH} / \mathrm{TH}$ stress that was observed from resistant $P$. columella (Alba et al., under review).

Furthermore, there was enrichment in molecular functions related to $\mathrm{Ca}^{2+}$ binding. This ion is a common secondary messenger inside the cells with important roles in signal transduction during several processes including immune response in molluscs (Tunholi-Alves et al., 2014). In addition, it is essential for shell formation and alteration of calcium levels in hemolymph during infection or due to $\mathrm{pH}$ regulation can result in shell hypocalcification (Tunholi et al., 2011, Tunholi et al., 2017, Tunholi-Alves et al., 2014). Thus, it is hypothesized here that enhanced capabilities to manage calcium balance is also linked with the resistance to $F$. hepatica and the tolerance to $\mathrm{pH} / \mathrm{TH}$ stress in $P$. columella, and might be somehow related to the characteristic pigmentation patterns displayed in the mantle of resistant snails as it is the site of shell formation (see Gutiérrez et al. (2003b)). 
The differential transcription effort towards stress/defense response observed in naïve resistant $P$. columella suggests that self-maintenance and survival is the preferred life strategy in this phenotype. However, energy budget constraints cause trade-off against other biological processes, as exemplified by reproductive constraints observed in some pathogen-resistant hosts, (e.g. Langand et al., 1998). The limited reproductive output specifically of the resistant phenotype of $P$. columella (Alba et al., under review) may be associated with the underrepresentation of biological process/functions/proteins related to protein synthesis, evident from both "omic" approaches (see Figure $2 \mathrm{C}$ and Table 1). Enhanced immune responsiveness may reconfigure intermediate metabolism towards a relative increase of the respiration rate, glycolysis, proteolysis and lipolysis (Lochmiller and Deerenberg, 2000), and increased defenses against stress (e.g. antioxidative enzymes (Freitas et al., 2006) may cause lower energy reserves (protein and glycogen content) and higher metabolic rates.

In the albumen gland of resistant snails, energy production through the respiratory chain and energy storage (synthesis of fatty acid) were indicated particularly active by the abundance of cytochrome b-c1 complex subunit 2 mitochondrial-like isoforms and of 3-oxoacyl- reductase FabG-like (catalyzes the first step of the fatty acid synthesis), respectively (see Table 1). Elevated representation of 4hydroxyphenylpyruvate dioxygenase-like may indicate an association with catabolism of aromatic amino acids, whose intermediates enter into the Kreb's cycle. These processes likely constrain the production of the protein components of the perivitelline fluid, that are normally deposited in eggs and directly involved in the sustainability of the embryos, a primary reproductive function of the albumen gland (Duncan, 1975, Geraerts and Joosse, 1984). Consequently, the reproductive output of resistant snails, whether in quantity (fecundity rates, net reproductive rate), quality (viable eggs) or in time (late reproductive peaks), might be affected especially because the albumen gland is also devoted to the synthesis of proteins involved in immunity and other functions (see Table 1). This then results in a tradeoff against reproduction, particularly egg production/viability (Stearns, 1992). Thus, results from this study may provide, at least in part, insights into the molecular basis of the reproductive constraints of resistant compared to susceptible snails (see Alba et al. (under review); Gutiérrez et al. (2002) for details).

Speculatively, the metabolic rearrangement and allocation of resources in the albumen gland of resistant snails, as proposed here, may relate to differences in neurotransmitter metabolism observed between $P$. columella phenotypes (see signaling proteins in Table 1). The presence of TBH suggests that 
471

472

473

474

475

476

477

478

479

480

481

482

483

484

485

486

487

488

489

490

491

492

493

494

495

496

497

498

499

500

501

tyramine and, mainly, octopamine are preferentially involved in neuroendocrine control of the albumen gland of resistant snails. To date, however, only a few studies (from bivalves) inform regarding a functional role of octopamine in molluscan reproduction (Blais et al., 2010). Yet other studies refer to potential involvement of octopamine in regulation of feeding and locomotion in gastropods (Ormshaw and Elliott, 2006, Vehovszky and Elliott, 2001, Wentzell et al., 2009) and, octopamine participates in the regulation of metabolism, ovulation and egg laying in insects and nematodes (Monastirioti, 2003, Monastirioti et al., 1996, Tao et al., 2016). Additionally, this neurotransmitter was also associated with stress responses in invertebrates. Increased TBH concentrations may be a stress marker in insects (Châtel et al., 2013). In free living nematodes a rise in octopamine levels allows metabolic rearrangements to maintain energy homeostasis during stress induced by starvation (Tao et al., 2016). Similarly, a significant increase of octopamine has been observed in the central nervous system of severely food-deprived Lymnaea stagnalis snails (Aonuma et al., 2017). The results of this study certainly warrant further studies of neurotransmitters concentration and their role in regulating allocation of resources and metabolic functions in the reproductive and immune functions of resistant and susceptible $P$. columella.

\subsection{Elevated representation of immune-related molecules in resistant snails}

Compared to susceptible snails, naïve resistant $P$. columella display an overall enhanced immune capacity based on novel and/or elevated expression of an arsenal of defense factors, including pathogen recognition/interacting molecules, particularly C-type lectins as wells as mannose and galactose binding lectins (see Figure $3 \mathrm{~B}$ ). The variety of up-regulated transcripts potentially able to interact with pathogens displayed by resistant snails may be advantageous given that the first step of any defense response requires recognition of the threat (Pinaud et al., 2019). C-type lectins, in particular, are known for recognition of carbohydrates that constitute pathogen-associated molecular patterns (PAMPs) like LPS and peptidoglycan. Once bound, lectins mediate immune activities ranging from microbe agglutination and opsonization to triggering signaling pathways for induction of phagocytosis and encapsulation (Vázquez-Mendoza et al. 2013; Pees et al., 2016). In snail-digenean interactions, C-type lectins from B. glabrata interact with antigens of S. mansoni sporocysts (Wu et al., 2017) and are expressed by resistant snails in response towards E. caproni infection (Guillou et al., 2007). Potentially, the great abundance of mannose binding lectins (see Figure 3B for details) increases the potential of resistant $P$. columella for rapid effective immune detection of $F$. hepatica, because the surface of sporocyst is mainly covered with $\mathrm{N}$-acetyl-D-glucosamine and $\alpha$-mannose (Georgieva et al., 2016). More 
502

503

504

505

506

507

508

509

510

511

512

513

514

515

516

517

518

519

520

521

522

523

524

525

526

527

528

529

530

531

532

effective parasite recognition in resistant $P$. columella may be contributed to further by highly abundant CD109. The B. glabrata homolog of this thioester-containing protein family member interacts with $S$. mansoni larvae (Wu et al., 2017).

Furthermore, abundant transcripts encoding cytokine such as G-CSFR, TGF1B and MIF, involved in the proliferation, recruitment and activation of immune cells provide a likely explanation for the effective cellular response that is reliably triggered in resistant snails in response to $F$. hepatica infection (Gutiérrez et al., 2003b). TGF1B belongs to a family of multifunctional cytokines found in different phyla that share a highly conserved signal transduction pathway and participates in the regulation of different biological functions including stress response and immune modulation (Huminiecki et al., 2009). MIF was recorded from several species of mollucs, the homolog of B. glabrata is present in hemocytes, and promotes cell aggregation and hemocyte proliferation, while inhibiting NO-dependent p53-mediated apoptosis. RNAi-mediated knockdown confirmed immune function of B. glabrata MIF, yielding increased parasite burden following exposure to S. mansoni (Baeza-Garcia et al., 2010). Likewise, in Oncomelania hupensis a more distantly related prosobranch gastropod, expression of MIF increased after challenge with Schistosoma japonicum and its involvement in the activation, differentiation and recruitment of hemocytes was demonstrated: RNAi knockdown of MIF decreased the proportion of phagocytic circulating hemocytes and restrains the migration of blood cells from the host towards the site of infection (Huang et al., 2017).

The abundance, in resistant snails, of transcripts related to pro-inflammatory signaling pathways (e.g. TLR/Myd88 and PCK) and with regulatory activities (e.g. LRR and IRF) is particularly significant and indicates that increased amounts of signaling components are available for a higher immune responsiveness as is associated with the resistant phenotype. Notably, PKC regulates differentiation and activation of snail hemocytes towards a phenotype more prompt to cellular reactions, particularly promoting increased production of $\mathrm{NO}$ and $\mathrm{H}_{2} \mathrm{O}_{2}$ levels (Humphries and Yoshino, 2008, Lacchini et al., 2006, Wright et al., 2006) and cell spreading (Humphries et al., 2001). According to Walker et al. (2010), PKC and ERK pathways are involved with focal adhesion kinase in cell adhesion, spreading and formation of lamellipodia, necessary for phagocytosis in L. stagnalis. TLRs are widely studied primary mediators of innate immunity that following recognition of PAMPs, activate highly conserved immune signaling pathways across many different animal phyla. Interestingly, the downstream components (Myd88 and $N F-k B$ ) of this signaling pathway were also significantly abundant in resistant snails (see Figures $2 B$ and 3B). In molluscs, TLRs can be activated, and expression up-regulated, after septic injury to promote 
hemocyte activation (for review see Brennan and Gilmore, 2018, Nie et al., 2018). Involvement in snailtrematode interactions was confirmed by a report showing that a TLR was highly expressed in hemocytes from a S. mansoni-resistant strain of B. glabrata and siRNA-mediated knockdown significantly reversed the resistant phenotype (Pila et al., 2016).

Other molecules involved in acute phase response and redox killing like ferritin, nitric oxide synthase and antioxidant enzymes are also significantly abundant in resistant snails. These may contribute to the orchestration of effective cellular cytotoxic immune responses that lead to parasite elimination in resistant $P$. columella. Hemocytes of a $B$. glabrata strain resistant to $S$. mansoni highly express ferritin prior parasite infection (Lockyer et al., 2012). Ferritin binds and regulates iron distribution. As part of an acute phase response, ferritin is up-regulated after microbial challenge for iron sequestration in order to deprive infecting microorganisms from iron acquisition and multiplication of pathogens (Ong et al., 2006). Ferritin also acts as antibacterial agent in mollusks (Zheng et al., 2016, Chen et al., 2016), remarkably different ferritin isoforms are induced in B. glabrata in a pathogen-specific manner (Deleury et al., 2012). Ferritin may affect the cellular balance of reactive oxygen species (ROS) hydrogen peroxide $\left(\mathrm{H}_{2} \mathrm{O}_{2}\right)$ and hydroxyl free radical $(\mathrm{OH})$ thereby regulating oxidative killing of trematode parasites in $B$. glabrata (Lockyer et al., 2012). In vertebrates and invertebrates, various nitric oxide synthase enzymes catalyze production of highly reactive nitric oxide (NO) for immune defense to effect killing of pathogens (Nathan and Shiloh, 2000; Wright et al. 2006). In Drosophila melanogaster, NO mediates signal transduction to activate a defense response to Gram-negative bacteria (Foley and O'Farrell, 2003). Particularly in snail-trematode interactions, killing of S. mansoni by B. glabrata hemocytes involves significant production of $\mathrm{NO}$ and $\mathrm{H}_{2} \mathrm{O}_{2}$ (Hahn et al., 2001b, Hahn et al., 2001a).

Resistant $P$. columella may benefit from higher constitutive antioxidant potential, as afforded by catalase and SOD, prior to parasite infection because up-regulation of catalase is essential to maintain redox balance and to resist bacterial infection in the clam Meretrix meretrix (Wang et al., 2013). Additionally, high constitutive levels of $\mathrm{Cu} / \mathrm{Zn}$ SOD are positively related to anti-parasite resistance in $B$. glabrata snails as this enzyme helps to focus the production of oxygen reactive species from superoxide radical toward $\mathrm{H}_{2} \mathrm{O}_{2}$, which is more effective at killing trematode larvae (Goodall et al., 2004, Lockyer et al., 2012).

The comparative proteomic analysis on products from the albumen gland, showed an overall higher abundance in resistant $P$. columella of two immune-effectors: LBP/BPI and G-type lysozyme. The G-type lysozymes are lytic proteins with potent activities against pathogens, mainly bacteria. These lysozymes 
are ubiquitously distributed across animal phylogeny, and have also been reported from several species of molluscs where they can be induced to function as immune effectors (Bathige et al., 2013, Guo and $\mathrm{He}, 2014$, Zhang et al., 2012). A significant increase of the expression of three G-type lysozymes was observed in S. japonicum-infected $O$. hupensis snails and suggests involvement in the defense against trematode parasites also (Zhang et al., 2012).

For the resistant strain of $P$. columella, the expression of $L B P / B P I$ is also of interest as this protein has been associated with snail parental investment in immune protection of offspring (Baron et al., 2013). Particularly, the albumen gland of B. glabrata produces an isoform of LBP/BPI that is contributed to the perivitelline fluid of snail eggs (Hathaway et al., 2010) and provides protection against oomycete infections (Baron et al., 2013). Thus, elevated levels of both immune effectors, lysozyme and LBP/BPI if contributed by the albumen gland of $P$. columella to the perivitelline fluid, may provide enhanced immune protection for snail embryos that develop inside eggs to potentially compensate for the limited reproductive outputs observed from resistant phenotype snails (Gutiérrez et al., 2002, Alba et al., under review).

\section{Conclusions}

This review of the complex interaction of $P$. columella with its trematode parasite $F$. hepatica, focused on the phenotypical, genetical and ecological features of the resistant snail phenotype that occurs in Cuban field populations, underscores the value of in-depth "omics" to reveal the underlying immunobiology. Accordingly, this paper also presents for the first time, a transcriptome of $P$. columella and, by combining different comparative omic analyses of resistant and susceptible snails, we characterized the molecular baseline of the constitutive biological profile behind the resistance to $F$. hepatica in naïve $P$. columella prior to infection.

Similar patterns observed from resistant snails at both the transcriptomic and the proteomic levels, from whole snails and albumen glands, respectively converged to reveal increased abundance of biological processes/transcripts/proteins involved in immune and stress responses and under-representation of functions/molecules involved in protein synthesis), that is interpreted to indicate an overall allocation of resources towards survival and self-maintenance in these snails. Specifically, the enhanced immune and stress responsiveness found at the molecular level offer a link between parasite resistance in $P$. columella and the increased tolerance observed in resistant populations to stress due to low $\mathrm{pH}$ and $\mathrm{TH}$ variation in the environment. The dedication of metabolic effort to immune and stress response, is 
594

595

596

597

598

599

600

601

602

603

604

605

606

607

608

609

610

611

612

613

614

615

616

617

618

619

620

621

indicated to be in detriment of protein synthesis/folding that, especially significant in case of the albumen gland, may amount to reproductive trade-offs and may explain, at least in part, the suggested fitness cost of heightened immune function in snail from Cuban populations of $P$. columella that are consistently resistant to $F$. hepatica infection.

However, characterization of differences between naïve resistant and susceptible $P$. columella snails is only a first step toward the elucidation of the molecular processes and specific mechanisms involved in the resistance to $F$. hepatica. Analyses of the immunobiological response following parasitic exposure is warranted, progressing to detailed investigation of the role of $P$. columella hemocytes in response to $F$. hepatica infection.

\section{Acknowledgments}

This study is set within the framework of the "Laboratoires d'Excellences (LABEX)" TULIP (ANR-10-LABX41). Authors acknowledge Dr. Silvain Pinaud and Dr. Ricardo Lebrón for valuable comments on the transcriptomic analyses. The authors would like to thank the insightful comments and suggestions made by the anonymous reviewers and by the editor that greatly helped in improving the manuscript. We are in debt to Dr. Coen Adema for the excellent editorial work.

\section{Funding sources}

Experiments from this study have been financially supported by ANR JCJC INVIMORY (number ANR 13JSV7-0009) from the French National Research Agency (ANR). AA was financed by the French Embassy in Cuba.

\section{Author's contributions:}

AA, GT, CC, JS, AAV, BG designed and performed the experiments and analysis, and participated in the reviewing process. AA, AAV, JS participated in snail breeding, and sample recollection. AA, GT: conducted the proteomic experiment and analyses. AA, CC, BG conducted the transcriptomic experiment and analyses. AA, GT, BG drafted the manuscript. All authors read and approved the final version of the manuscript.

All data generated or analyzed during this study are included in this article [and its supplementary information files]. All RNAseq data is available online under the following accession numbers: NCBI-SRA

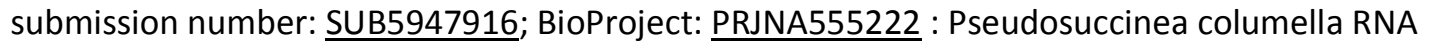


622

623

624

625

626

627

628

629

630

631

632

633

634

635

636

637

638

639

640

641

642

643

644

645

646

647

648

sequencing; BioSample: SAMN12305757: Pseudosuccinea columella RNAseq (TaxID: 31228). Full and simplified transcriptomes of $P$. columella snail are also available at: http://ihpe.univ-perp.fr/acces-auxdonnees/

\section{Declarations of interest:}

Author's declare that there no conflict of interest exists

\section{Reference}

Alba, A., Vázquez, A.A., Sánchez, J., Duval, D., Hernández, H., Sabourin, E., Vittecoq, M., Hurtrez-Boussés, S., Gourbal, B. 2018. Fasciola hepatica - Pseudosuccinea columella interaction: effect of increasing parasite doses, successive exposures and geographic origin on the infection outcome of naturallyresistant and susceptible snails from Cuba. Parasite Vect. 11, 559.

Alba, A., Vázquez, A.A., Sánchez, J., Fraga, J., Martínez, E., Hernández, H., Marcet, R., Figueredo, M., Sarracent, J. 2016. Assessment of the FasciMol-ELISA in the detection of the trematode Fasciola hepatica in field-collected Galba cubensis: a novel tool for the malacological survey of fasciolosis transmission. Parasite Vect. 9, 22; doi: 10.1186/s13071-016-1303-1.

Alba, A., Vázquez, A.A., Sánchez, J., Lounnas, M., Pointier, J.P., Hurtrez-Boussès, S., Gourbal, B. Patterns of distribution, population genetics and ecological requirements of field-occurring resistant and susceptible Pseudosuccinea columella snails to Fasciola hepatica in Cuba. Under review by Sci Reports.

Aonuma, H., Kaneda, M., Hatakeyama, D., Watanabe, T., Lukowiak, K., Ito, E. 2017. Weak involvement of octopamine in aversive taste learning in a snail. Neurobiol Learn Mem. 141, 189-198.

Baeza-Garcia, A., Pierce, R. J., Gourbal, B., Werkmeister, E., Colinet, D.J.M., Reichhart, J.M., Dissous, C., Coustau, C. 2010. Involvement of the cytokine MIF in the snail host immune response to the parasite Schistosoma mansoni. PLoS Pathog. 6, e1001115.

Bargues, M.D., Mas-Coma, S. 1997. Phylogenetic analysis of Lymnaeid snails based on 18 S rDNA sequences. Mol Biol Evol. 14, 569-77.

Baron, O.L., Van West, P., Industri, B., Ponchet, M., Dubreuil, G., Gourbal, B., Reichhart, J.M., Coustau, C. 2013. Parental transfer of the antimicrobial protein LBP/BPI protects Biomphalaria glabrata eggs against oomycete infections. PLoS Pathog. 9, e1003792. 
649

650

651

652

653

654

655

656

657

658

659

660

661

662

663

664

665

666

667

668

669

670

671

672

673

674

Bathige, S. D., Umasuthan, N., Whang, I., Lim, B. S., Jung, H. B., Lee, J. 2013. Evidences for the involvement of an invertebrate goose-type lysozyme in disk abalone immunity: cloning, expression analysis and antimicrobial activity. Fish Shellfish Immunol. 35, 1369-1379.

Blais, V., Bounif, N., Dubé, F. 2010. Characterization of a novel octopamine receptor expressed in the surf clam Spisula solidissima. Gen Comp Endocrinol. 167, 215-227.

Brennan, J.J., Gilmore, T.D. 2018. Evolutionary origins of Toll-like receptor signaling. Mol Biol Evol. 35, 1576-1587.

Brown, D.S. 1994. Freshwater snails of Africa and their medical importance. London, UK, Taylor and Francis.

Buddenborg, S.K., Bu, L., Zhang, S.-M., Schilkey, F.D., Mkoji, G.M., Loker, E.S. 2017. Transcriptomic responses of Biomphalaria pfeifferi to Schistosoma mansoni: investigation of a neglected African snail that supports more S. mansoni transmission than any other snail species. PLoS Negl Trop Dis. 11, e0005984.

Calienes, A.F., Fraga, J., Pointier, J.P., Yong, M., Sánchez, J., Coustau, C., Gutiérrez, A., Théron, A. 2004. Detection and genetic distance of resistant populations of Pseudosuccinea columella (Mollusca: Lymnaeidae) to Fasciola hepatica (Trematoda: Digenea) using RAPD markers. Acta Trop. 92, 83-87.

Conesa, A., Götz, S., García-Gómez, J. M., Terol, J., Talón, M., Robles, M. 2005. Blast2GO: a universal tool for annotation, visualization and analysis in functional genomics research. Bioinformatics. 21, 36743676.

Correa, A.C., Escobar, J.S., Noya, O., Velázquez, L.E., González-Ramírez, C., Hurtrez-Boussès, S., Pointier, J.P. 2011. Morphological and molecular characterization of Neotropic Lymnaeidae (Gastropoda: Lymnaeoidea), vectors of fasciolosis. Infect Genet Evol. 11, 1978-1988.

Cowie, R. 2001. Invertebrate invasions on Pacific Islands and the replacement of unique native faunas: a synthesis of the land and freshwater snails. Biol Invasions. 3, 119-136.

Cruz-Reyes, A., Malek, E. 1987. Suitability of six lymnaeid snails for infection with Fasciola hepatica. Vet Parasitol. 24, 203-210. 
675

676

677

678

679

680

681

682

683

684

685

686

687

688

689

690

691

692

693

694

695

696

697

698

699

Cucher, M., Carnevale, S., Prepelitchi, L., Labbé, J., Wisnivesky-Colli, C. 2006. PCR diagnosis of Fasciola hepatica in field-collected Lymnaea columella and Lymnaea viatrix snails. Vet Parasitol. 137, 74-82.

Châtel, A., Murillo, L., Bourdin, C. M., Quinchard, S., Picard, D., Legros, C. 2013. Characterization of tyramine $\beta$-hydroxylase, an enzyme upregulated by stress in Periplaneta americana. J Mol Endocrinol. 50, 91-102.

Chen, G., Zhang, C., Wang, Y., Guo, C., Sang, F., Wang, C. 2016. Identification and characterization of a ferritin gene involved in the immune defense response of scallop Chlamys farreri. Fish Shellfish Immunol. 55, 1-9.

Dar, Y., Lounnas, M., Djuikwo, F., Teukeng, F. F., Mouzet, R., Courtioux, B., Hurtrez-Boussès, S., Vignoles, P., Dreyfuss, G., Rondelaud, D. 2013. Variations in local adaptation of allopatric Fasciola hepatica to French Galba truncatula in relation to parasite origin. Parasitol Res. 112, 2543-2549.

Dar, Y., Rondelaud, D., Vignoles, P., Dreyfuss, G. 2014. Fasciola hepatica: development of redial generations in experimental infections of Pseudosuccinea columella. Parasitol Res. 113, 2467-2473.

Deleury, E., Dubreuil, G., Elangovan, N., Wajnberg, E., Reichhart, J. M., Gourbal, B., Duval, D., Baron, O. L., Gouzy, J., Coustau, C. 2012. Specific versus non-specific immune responses in an invertebrate species evidenced by a comparative de novo sequencing study. PLoS One. 7, e32512.

Demas, G.E., Adamo, S.A., French, S.S. 2011. Neuroendocrine-immune crosstalk in vertebrates and invertebrates: implications for host defence. Functional Ecol. 25, 29-39.

Duncan, C.J. 1975. Pulmonates, New York, Academic Press.

Foley, E., O'farrell, P.H. 2003. Nitric oxide contributes to induction of innate immune responses to gramnegative bacteria in Drosophila. Genes Dev. 17, 115-125.

Freitas, R., Pires, A., Moreira, A., Wrona, F.J., Figueira, E., Soares, A.M. 2006. Biochemical alterations induced in Hediste diversicolor under seawater acidification conditions. Mar Environ Res. 117, 75-84.

Gasteiger, E.A.G., Hoogland, C., Ivanyi, I., Appel, R.D., Bairoch, A. 2013. ExPASy: the proteomics server for in-depth protein knowledge and analysis. Nucleic Acids Res. 31, 3784-3788. 
700

701

702

703

704

705

706

707

708

709

710

711

712

713

714

715

716

717

718

719

720

721

722

Georgieva, K., Georgieva, L., Mizinska-Boevska, Y., Stoitsova, S.R. 2016. Study of surface carbohydrates in Galba truncatula tissues before and after infection with Fasciola hepatica. Mem Inst Oswaldo Cruz. $111,475-483$.

Geraerts, W.P.M., Joosse, J. 1984. Freshwater snails (Basommatophora). In: Tompa, A.S., Verdonk, N.H., Van Den Biggelaar, J.A.M. (eds.) The Mollusca. Orlando: Academic Press.

Giardine, B., Riemer, C., Hardison, R.C., Burhans, R., Elnitski, L., Shah, P., Zhang, Y., Blankenberg, D., Albert, I., Taylor, J., Miller, W., Kent, W.J., Nekrutenko, A. 2005. Galaxy: a platform for interactive largescale genome analysis. Genome Res. 15, 1451-1455.

Goodall, C.P., Bender, R.C., Broderick, E.J., Bayne, C.J. 2004. Constitutive differences in Cu/Zn superoxide dismutase mRNA levels and activity in hemocytes of Biomphalaria glabrata (Mollusca) that are either susceptible or resistant to Schistosoma mansoni (Trematoda). Mol Biochem Parasitol. 137, 321-328.

Grabher, M.G., Haas, B.J., Yassour, M., Levin, J.Z., Thompson, D.A., Amit, I., Adiconis, X., Fan,L., Raychowdhury, R., Zeng, Q., Chen, Z., Mauceli, E., Hacohen, N., Gnirke, A., Rhind, N., Di Palma, F., Birren, B.W., Nusbaum, C., Lindblad-Toh, K., Friedman, N., Regev, A. 2011. Full-length transcriptome assembly from RNA-Seq data without a reference genome. Nat Biotechnol. 29, 644-652.

Grabner, D.S, Mohamed, F., Nachev, M. Meabed, E.M, Sabry, A.H., Sures, B. 2014. Invasion biology meets parasitology: a case study of parasite spill-back with Egyptian Fasciola gigantica in the invasive snail Pseudosuccinea columella. PLoS One. 9, e88537.

Guillou, F., Mitta, G., Galinier, R., Coustau, C. 2007. Identification and expression of gene transcripts generated during an anti-parasitic response in Biomphalaria glabrata. Dev Comp Immunol. 31, 657-671.

Guo, Y., He, H. 2014. Identification and characterization of a goose-type lysozyme from sewage snail Physa acuta. Fish Shellfish Immunol. 39, 321-325.

Gutiérrez, A., Hernández, D.F., Sánchez, J. 2005a. Variations of snail's abundances in two water bodies harboring strains of Pseudosuccinea columella resistant and susceptible to Fasciola hepatica miracidial infection in Pinar del Rio province, Cuba. Mem Inst Oswaldo Cruz. 100, 725-727.

Gutiérrez, A., Perera, G., Yong, M., Lin, W. 2002. Fasciola hepatica (Trematoda: Digenea): its effect on the life history traits of Pseudosuccinea columella (Gastropoda: Lymnaeidae), an uncommon interaction. Parasitol Res. 88, 535-539. 
Gutiérrez, A., Pointier, J.P., Fraga, J., Jobet, E., Modat, S., Pérez, R.T., Yong, M., Sanchez, J., Loker, E.S., Théron, A. 2003a. Fasciola hepatica: identification of molecular markers for resistant and susceptible Pseudosuccinea columella snail hosts. Exp Parasitol. 105, 211-218.

Gutiérrez, A., Pointier, J.P., Yong, M., Sánchez, J., Théron, A. 2003b. Evidence of phenotypic differences between resistant and susceptible isolates of Pseudosuccinea columella (Gastropoda: Lymnaeidae) to Fasciola hepatica (Trematoda: Digenea) in Cuba. Parasitol Res. 90, 129-34.

Gutiérrez, A., Vázquez, A.A., Hevia, Y., Sánchez, J., Correa, A.C., Hurtrez-Bouseès, S., Pointier, J.P., Théron, A. 2011. First report of larval stages of Fasciola hepatica in a wild population of Pseudosuccinea columella from Cuba and the Caribbean. J Helminthol. 85, 109-11.

Gutiérrez, A., Yong, M., Sanchez, J., Wong, M., Pointier, J.P. 2005b. Competition between Fossaria cubensis and two isolates (susceptible and resistant to Fasciola hepatica) of Pseudosuccinea columella under laboratory conditions. Haliotis. 35, 1 - 11.

Hahn, U.K., Bender, R.C., Bayne, C.J. 2001a. Involvement of nitric oxide in killing of Schistosoma mansoni sporocysts by hemocytes from resistant Biomphalaria glabrata. J Parasitol. 87, 778-785.

Hahn, U.K., Bender, R.C., Bayne, C.J. 2001b. Killing of Schistosoma mansoni sporocysts by hemocytes from resistant Biomphalaria glabrata: role of reactive oxygen species. J Parasitol. 87, 292-299.

Hathaway, J.J., Adema, C.M., Stout, B.A., Mobarak, C.D., Loker, E.S. 2010. Identification of protein components of egg masses indicates parental investment in immunoprotection of offspring by Biomphalaria glabrata (Gastropoda, Mollusca). Dev Comp Immunol. 34, 425-435.

Huang, S., Cao, Y., Lu, M., Peng, W., Lin, J., Tang, C., Tang, L. 2017. Identification and functional characterization of Oncomelania hupensis macrophage migration inhibitory factor involved in the snail host innate immune response to the parasite Schistosoma japonicum. Int J Parasitol. 47, 485-499.

Humbert, E., Coustau, C. 2001. Refractoriness of host haemocytes to parasite immunosuppressive factors as a putative resistance mechanism in the Biomphalaria glabrata-Echinostoma caproni system. Parasitology. 122, 651-660.

Huminiecki, L., Goldovsky, L., Freilich, S., Moustakas, A., Ouzounis, C., Heldin, C.H. 2009. Emergence, development and diversification of the TGF-beta signalling pathway within the animal kingdom. BMC Evol Biol. 9, 28. 
Humphries, J.E., Elizondo, L., Yoshino, T.P. 2001. Protein kinase C regulation of cell spreading in the molluscan Biomphalaria glabrata embryonic (Bge) cell line. Biochim Biophys Acta. 1540, 243-252.

Humphries, J. E., Yoshino, T.P. 2008. Regulation of hydrogen peroxide release in circulating haemocytes of the planorbid snail Biomphalaria glabrata. Dev Comp Immunol. 32, 554-562.

Khan, M.K., Sajid, M.S., Riaz, H., Ahmad, N.E., He, L., Shahzad, M., Hussain, A., Khan, M.N., Iqbal, Z., Zhao, J. 2013. The global burden of fasciolosis in domestic animals with an outlook on the contribution of new approaches for diagnosis and control. Parasitol Res. 112, 2421-30.

Lacchini, A.H., Davies, A.J., Mackintosh, D., Walker, A.J. 2006. beta-1, 3-glucan modulates PKC signalling in Lymnaea stagnalis defence cells: a role for PKC in $\mathrm{H} 2 \mathrm{O} 2$ production and downstream ERK activation. J Exp Biol. 209, 4829-4840.

Langand, J., Jourdane, J., Coustau, C., Delay, B., Morand, S. 1998. Cost of resistance, expressed as a delayed maturity, detected in the host-parasite system Biomphalaria glabrata /Echinostoma caproni. Heredity. 80, 320-325.

Langmead, B., Salzberg, S.L. 2012. Fast gapped-read alignment with Bowtie 2. Nature Meth. 9,357-359.

Li, W., Godzik, A. 2006. Cd-hit: a fast program for clustering and comparing large sets of protein or nucleotide sequences. Bioinformatics. 22, 1658-1659.

Lockyer, A.E., Emery, A.M., Kane, R.A., Walker, A.J., Mayer, C.D., Mitta, G., Coustau, C., Adema, C.M., Hanelt, B., Rollinson, D., Noble, L.R., Jones, C.S. 2012. Early differential gene expression in haemocytes from resistant and susceptible Biomphalaria glabrata strains in response to Schistosoma mansoni. PLoS One. 7, e51102.

Lochmiller, R.L., Deerenberg, C. 2000. Trade-offs in evolutionary immunology: just what is the cost of immunity? OIKOS. 88, 87-98.

Lounnas, M., Correa, A.C., Vázquez, A.A., Dia, A., Escobar, J.S., Nicot, A., Arenas, J., Ayaqui, R., Dubois, M. P., Gimenez, T., Gutiérrez, A., González-Ramírez, C., Noya, O., Prepelitchi, L., Uribe, N., Wisnivesky-Colli, C., Yong, M., David, P., Loker, E.S., Jarne, P., Pointier, J.P., Hurtrez-Boussès, S. 2017. Self-fertilization, long-distance flash invasion and biogeography shape the population structure of Pseudosuccinea columella at the worldwide scale. Mol Ecol. 26, 887-903. 
Love, M.I., Huber, W., Anders, S. 2014. Moderated estimation of fold change and dispersion for RNA-seq data with DESeq2. Genome Biol. 15, 550.

Macmicking, J., Xie, Q.W., Nathan, C. 1997. Nitric oxide and macrophage function Annu Rev Immunol., $15,323-350$.

Marchler-Bauer, A., Derbyshire, M.K., Gonzales, N.R., Lu, S., Chitsaz, F., Geer, L.Y., Geer, R.C., He, J., Gwadz, M., Hurwitz, D.I., Lanczycki, C.J., Lu, F., Marchler, G.H., Song, J.S., Thanki, N., Wang, Z., Yamashita, R.A., Zhang, D., Zheng, C., Bryant, S.H. 2015. CDD: NCBI's conserved domain database. Nucleic Acids Res. 43, 222-226.

Mas-Coma, S., Bargues, M.D. \& Valero, M.A. 2009. Chapter 2. Fasciola, lymnaeids and human fascioliasis, with a global overview on disease transmission, epidemiology, evolutionary genetics, molecular epidemiology and control. Adv Parasitol. 69, 41-146.

Matozzo, V., Chinellato, A., Munari, M., Finos, L., Bressan, M., Marin, M.G. 2012. First evidence of immunomodulation in bivalves under seawater acidification and increased temperature. PLoS One. 7, e33820.

Mattews, P.G.D. 2017. Acid-base regulation in insect hemolymph. In: Weihrauch, D., O'Donell, M. (eds.) Acid-base balance and nitrogen excretion in invertebrates: mechanisms and strategies in various invertebrate groups with considerations of challenges caused by ocean acidification. Cham, Switzerland: Springer International Publishing AG.

Mehmood, K., Zhang, H., Sabir, A.J., Abbas, R.Z., ljaz, M., Durrani, A.Z., Saleem, M.H., Ur Rehman, M., Iqbal, M.K., Wang, Y., Ahmad, H.I., Abbas, T., Hussain, R., Ghori, M.T., Ali, S., Khan, A.U., Li, J. 2017. A review on epidemiology, global prevalence and economical losses of fasciolosis in ruminants. Microb Pathog. 109, 253-262.

Meunier, C., Hurtrez-Boussès, S., Jabbour-Zahab, R., Durand, P., Rondelaud, D., Renaud, F. 2004. Field and experimental evidence of preferential selfing in the freshwater mollusc Lymnaea truncatula (Gastropoda, Pulmonata). Heredity. 92, 316-322.

Molloy, J. B., Anderson, G.R. 2006. The distribution of Fasciola hepatica in Queensland, Australia, and the potential impact of introduced snail intermediate hosts. Vet Parasitol. 137, 62-66. 
810

811

812

813

814

815

816

817

818

819

820

821

822

823

824

825

826

827

828

829

830

831

832

833

834

Monastirioti, M. 2003. Distinct octopamine cell population residing in the CNS abdominal ganglion controls ovulation in Drosophila melanogaster. Dev Biol. 264, 38-49.

Monastirioti, M., Linn, C.E.J., White, K. 1996. Characterization of Drosophila tyramine beta-hydroxylase gene and isolation of mutant flies lacking octopamine. J Neurosci. 16, 3900-3911.

Mu, H., Sun, J., Heras, H., Chu, K.H., Qiu, J.W. 2017. An integrated proteomic and transcriptomic analysis of perivitelline fluid proteins in a freshwater gastropod laying aerial eggs. J Proteomics. 115, 22-30.

Nathan, C., Shiloh, M. U. 2000. Reactive oxygen and nitrogen intermediates in the relationship between mammalian hosts and microbial pathogens. Proc Natl Acad Sci. 97, 8841-8848.

Nicot, A., Dubois, M.P., Debain, C., David, P., Jarne, P. 2008. Characterization of 15 microsatellite loci in the pulmonate snail Pseudosuccinea columella (Mollusca, Gastropoda). Mol Ecol. 8, 1281-1284.

Nie, L., Cai, S.Y., Shao, J.Z., Chen, J. 2018. Toll-like receptors, associated biological roles, and signaling networks in non-mammals. Front Immunol. 9, 1523-1542.

Ong, S.T., Ho, J.Z., Ho, B., Ding, J.L. 2006. Iron-withholding strategy in innate immunity. Immunobiology. 211, 295-314.

Ormshaw, J.C., Elliott, C.J. 2006. Octopamine boosts snail locomotion: behavioral and cellular analysis. Invert Neurosci. 6, 215-220.

Paraense W.L, Correa L.R. 1963. Variation in susceptibility of populations of Australorbis glabratus to a strain of Schistosoma mansoni. Rev Inst Med Trop Sao Paulo. 5, 15-22

Patro, R., Duggal, G., Love, M.I., Irizarry, R.A., Kingsford, C. 2017. Salmon provides fast and bias-aware quantification of transcript expression. Nature Meth. 14, 417-419.

Pees, B., Yang, W., Zarate-Potes, A., Schulenburg, H., Dierking, K. 2016. High innate immune specificity through diversified C-type Lectin-like domain proteins in invertebrates. J Innate Immun. 8, 129-42.

Pila, E.A., Tarrabain, M., Kabore, A.L., Hanington, P.C. 2016. A novel Toll-like receptor (TLR) influences compatibility between the gastropod Biomphalaria glabrata, and the digenean trematode Schistosoma mansoni. PLoS Pathog. 12, e1005513. 
Pinaud, S., Portet, A., Allienne, J.F., Belmudes, L., Saint-Beat, C., Arancibia, N., Galinier, R., Du Pasquier L., Duval, D., Gourbal, B. 2019. Molecular characterisation of immunological memory following homologous or heterologous challenges in the schistosomiasis vector snail, Biomphalaria glabrata. Dev Comp Immunol. 92, 238-252.

Pointier, J.P. 2008. Guide to the freshwater Molluscs of the Leasser Antilles., Hackenheim, Germany, ConchBooks.

Pointier, J.P., Coustau, C., Rondelaud, D., Théron, A. 2007. Pseudosuccinea columella (Say 1817) (Gastropoda, Lymnaeidae), snail host of Fasciola hepatica: first record for France in the wild. Parasitol Res. 101, 1389-1392.

Pointier, J.P., Marquet, G. 1990. Taxonomy and distribution of freshwater mollusks of French Polynesia. Japanese J Malacol. 48, 147-160.

Salazar, L., Estrada, V.E., Velásquez, L.E. 2006. Effect of the exposure to Fasciola hepatica (Trematoda: Digenea) on life history traits of Lymnaea cousini and Lymnaea columella (Gastropoda: Lymnaeidae). Exp Parasitol. 114, 77-83.

Sánchez, R., Perera, G., Sánchez, J. 1995. Cultivo de Fossaria cubensis (Pfeiffer) (Pulmonata: Lymnaeidae) hospedero intermediario de Fasciola hepatica (Linnaeus) en Cuba. Rev Cubana Med Trop. 47, 71-3.

Sen, G., Mandal, C., Chowdhury, M. 1992. Albumen gland of the snail Achatina fulica is the site for synthesis of Achatinin H, a sialic acid binding lectin. Mol Cell Biochem. 117, 133-138.

Simão, F.A., Waterhouse, R.M., loannidis, P., Kriventseva, E.V., Zdobnov, E.M. 2015. BUSCO: assessing genome assembly and annotation completeness with single-copy orthologs. Bioinformatics. doi: 10.1093/bioinformatics/btv351.

Tao, J., Ma, Y.C., Yang, Z.S., Zou, C.G., Zhang, K.Q. 2016. Octopamine connects nutrient cues to lipid metabolism upon nutrient deprivation. Sci Adv. 2, e1501372.

Tunholi-Alves, V.M., Tunholi, V.M., Garcia, J.S., Costa-Neto, S.F., Maldonado, A., Santos, M.A., Thiengo, S.C., Pinheiro, J. 2014. Changes in the calcium metabolism of Biomphalaria glabrata experimentally infected with Angiostrongylus cantonensis. J Helminthol. 88, 160-165. 
861

862

863

864

865

866

867

868

869

870

871

872

873

874

875

876

877

878

879

880

881

882

883

884

885

886

887

Tunholi, V.M., Lustrino, D., Tunholi-Alves, V.M., Garcia, J.S., Mello-Silva, C.C., Maldonado, A.J., Rodrigues, M.D.L., Pinheiro, J. 2011. Influence of Echinostoma paraensei (Lie and Basch, 1967) infection on the calcium content in Biomphalaria glabrata (Say, 1818). Exp Parasitol. 129, 266-269.

Tunholi, V.M., Tunholi-Alves, V.M., Monteiro, C.O., Silva, L.C.D., Dolinski, C.M., Castro, R.N., Bittencourt, V.R.E.P., Silva, J.P.D., Freire Martins, I.V. 2017. Biological, biochemical and histological features of Bradybaena similaris (Gastropoda: Pulmonata) infected by Heterorabditis indica (Rhabditida: Heterorhabditidae) strain LPP1. Exp Parasitol. 179, 28-35.

Vázquez, A.A., Alda, P., Lounnas, M., Sabourin, E., Alba, A., Pointier, J.P., Hurtrez-Boussès, S. 2018. Lymnaeid snails hosts of Fasciola hepatica and Fasciola gigantica (Trematoda: Digenea): a worldwide review. CAB Reviews. 13, 062.

Vázquez, A.A., Hevia, Y., Sánchez, J. 2009. Distribución y preferencia de hábitats de moluscos hospederos intermediarios de Fasciola hepatica en Cuba. Rev Cubana Med Trop. 61, 248-53.

Vázquez, A.A., Sánchez, J. 2015. Clave ilustrada y comentada para la identificación de moluscos gastrópodos fluviales de Cuba. Rev Cubana Med Trop. 67, 231-243.

Vázquez, A.A., Sánchez, J., Alba, A., Pointier, J.P., Hurtrez-Boussés, S. 2015. Natural prevalence in Cuban populations of the lymnaeid snail Galba cubensis infected with the liver fluke Fasciola hepatica: small values do matter. Parasitol Res. 114, 4205-10

Vázquez, A.A., Sánchez, J., Pointier, J.P., Théron, A., Hurtrez-Boussès, S. 2014. Fasciola hepatica in Cuba: compatibility of different isolates with two intermediate intermediate hosts, Galba cubensis and Pseudosuccinea columella. J Helminthol. 88, 434-440.

Vázquez-Mendoza, A., Carrero, J.C., Rodriguez-Sosa, M. 2013. Parasitic infections: a role for C-type lectins receptors. Biomed Res Int. 2013, 456352.

Vehovszky, A., Elliott, C.J. 2001. Activation and reconfiguration of fictive feeding by the octopaminecontaining modulatory OC interneurons in the snail Lymnaea. J Neurophysiol. 86, 792-808.

Vergote, D., Bouchut, A., Sautière, P.E., Roger, E., Galinier, R., Rognon, A., Coustau, C., Salzet, M., Mitta, G. 2005. Characterisation of proteins differentially present in the plasma of Biomphalaria glabrata susceptible or resistant to Echinostoma caproni. Int J Parasitol. 35, 215-224. 
888

889

890

891

892

893

894

895

896

897

898

899

900

901

902

903

904

905

906

907

908

909

910

911

912

913

Vignoles, P., Dreyfuss, G., Rondelaud, D. 2015. Fasciola hepatica: comparative metacercarial productions in experimentally-infected Galba truncatula and Pseudosuccinea columella. Parasite. 22, 1-6.

Walker, A.J., Lacchini, A.H., Sealey, K.L., Mackintosh, D., Davies, A.J. 2010. Spreading by snail (Lymnaea stagnalis) defence cells is regulated through integrated PKC, FAK and Src signaling. Cell Tissue Res. 341, 131-145.

Wang, C., Yue, X., Lu, X., Liu, B. 2013. The role of catalase in the immune response to oxidative stress and pathogen challenge in the clam Meretrix meretrix. Fish Shellfish Immunol. 34, 91-99.

Wentzell, M.M., Martínez-Rubio, C., Miller, M.W., Murphy, A.D. 2009. Comparative neurobiology of feeding in the opisthobranch sea slug, Aplysia, and the pulmonate snail, Helisoma: evolutionary considerations. Brain Behav Evol. 74, 219-230.

Wright, B., Lacchini, A.H., Davies, A.J., Walker, A.J. 2006. Regulation of nitric oxide production in snail (Lymnaea stagnalis) defence cells: a role for PKC and ERK signalling pathways. Biol Cell. 96, 265-278.

Wu, X.J., Dinguirard, N., Sabat, G., Lui, H.D., Gonzalez, L., Gehring, M., Bickham-Wright, U., Yoshino, T.P. 2017. Proteomic analysis of Biomphalaria glabrata plasma proteins with binding affinity to those expressed by early developing larval Schistosoma mansoni. PLoS Pathog. 13, e1006081.

Zhang, S. H., Zhu, D.D., Chang, M.X., Zhao, Q.P., Jiao, R., Huang, B., Fu, J.P., Liu, Z.X., Nie, P. 2012. Three goose-type lysozymes in the gastropod Oncomelania hupensis: cDNA sequences and lytic activity of recombinant proteins. Dev Comp Immunol. 36, 241-246.

Zheng, L., Liu, Z., Wu, B., Dong, Y., Zhou, L., Tian, J., Sun, X., Yang, A. 2016. Ferritin has an important immune function in the ark shell Scapharca broughtonii. Dev Comp Immunol. 59, 15-24.

\section{Legends to figures and supplementary data}

Figure 1. Mantle pigmentation pattern of susceptible (A: Aurora, B: Negrines) and resistant (C: Babiney, D: La Coca, E: El Azufre, F: La Palma) Pseudosuccinea columella populations to Fasciola hepatica infection. The arrows indicate the characteristic band of small sharp spots in the mid-region of the mantle of resistant snails. (Photos: Laboratory of Malacology, Institute "Pedro Kouri" of Tropical Medicine). 
914

915

916

917

918

919

920

921

922

923

924

925

926

927

928

929

930

931

932

933

934

935

936

937

938

939

940

941

942

943

944

Figure 2. A) Enriched biological process and B) molecular functions of Pseudosuccinea columella transcriptome that are involved (overrepresented; in red) in the resistant phenotype. C) Enriched biological process and molecular functions of $P$. columella transcriptome particularly underrepresented (in blue) in the resistant phenotype. Each bar represents the percentage of unisequences found in the test data (over or under-represented transcripts in resistant $P$. columella) according to their GO terms.

Figure 2. Immune-related A) under- (in blue) and B) over- (red, right) represented transcripts in resistant Pseudosuccinea columella. C) Overrepresented transcripts related to acid-base regulation in resistant $P$. columella. Different colors within the same bar account for different variants within the same family of transcripts. Only transcripts with known homologs are shown. A2M: $\alpha$-2-macroglobulin; BANK: B-cell scaffold with ankyrin repeats-like isoform X1; BPI: bactericidal/permeability increasing protein; G-CSFR: granulocyte colony stimulatory factor; Ig: immunoglobulin; IL: interleukin; IFN: interferon; IRF: interferon regulatory factors; LRR: leucine rich repeats; MIF: macrophage migratory inhibitory factor; Myd88: myeloid differentiation primary response; MZB1: marginal zone B- and B1-cell-specific -like; PKC: protein kinase C; PTAFR: platelet-activating factor receptor-like; PECAM: platelet endothelial cell adhesion molecule; SAMHD1: deoxynucleoside triphosphate triphosphohydrolase SAMHD1; TGF: transforming growth factor; TLR: toll-like receptor; TNF: tumor necrosis factor.

Figure 3. 2D-electrophoretic profiles of the albumen gland of Pseudosuccinea columella resistant (gel on the left) and susceptible (gel on the right) to Fasciola hepatica infection. Spots identified only in the resistant or susceptible strains are indicated in red and green, respectively. Spots with significant fourfold difference between the two strains are indicated in blue, only on the gel corresponding to the strain in which they are overrepresented. Next to each spot is written the four-digit identification code used in the Table 1 and Supplementary File 3. The white rectangle within the gels represents an area of highly abundant proteins with several isoforms left aside of the differential analysis as its complexity impede the quantitative analysis and proper spot and protein identification.

Supplementary data 1: Excel files with the detailed DESeq2- information and annotation description (Blast2GO information) of the 6876 over- (S1A) and under- (Table S1B) represented transcripts of Pseudosuccinea columella showing more than 2-fold differential-expression and $P$ adjusted $<0.05$ between resistant and susceptible phenotypes to Fasciola hepatica infection. In addition, lists relating the differentially-expressed transcripts identified as putatively involved in immunity (i.e. defense response, wound healing and inflammation) and in relation to acid-base balance (i.e. carbonbicarbonate buffering and ion transportation) are also included in different sheets. 
945 Supplementary data 2: Excel files showing the table results of the enrichment analyses on

946 Pseudosuccinea columella transcriptome involving biological processes or molecular functions, and 947 considering separately over- (S2A) and under (S2B) -expressed transcript data on resistant snails to 948 Fasciola hepatica infection. Fisher's Exact Test run on Blast2GO software was used for analyses and a 949 particular GO term was considered to be enriched when $P$ and false discovery rate $(F D R)<0.05$.

950 Supplementary data 3: Excel file showing details on the analysis and further identification of the

951 differentially represented proteins of the albumen gland between Pseudosuccinea columella susceptible 952 and resistant to Fasciola hepatica, identified on 2D-electrophoresis (more than 4-fold of quantitative 953 differences; $P<0.01)$. $\mathrm{Html}$ files containing the information on MS/MS spectrometry analysis from the 954 PISSARO platform facility (University of Rouen, France) are also included. 

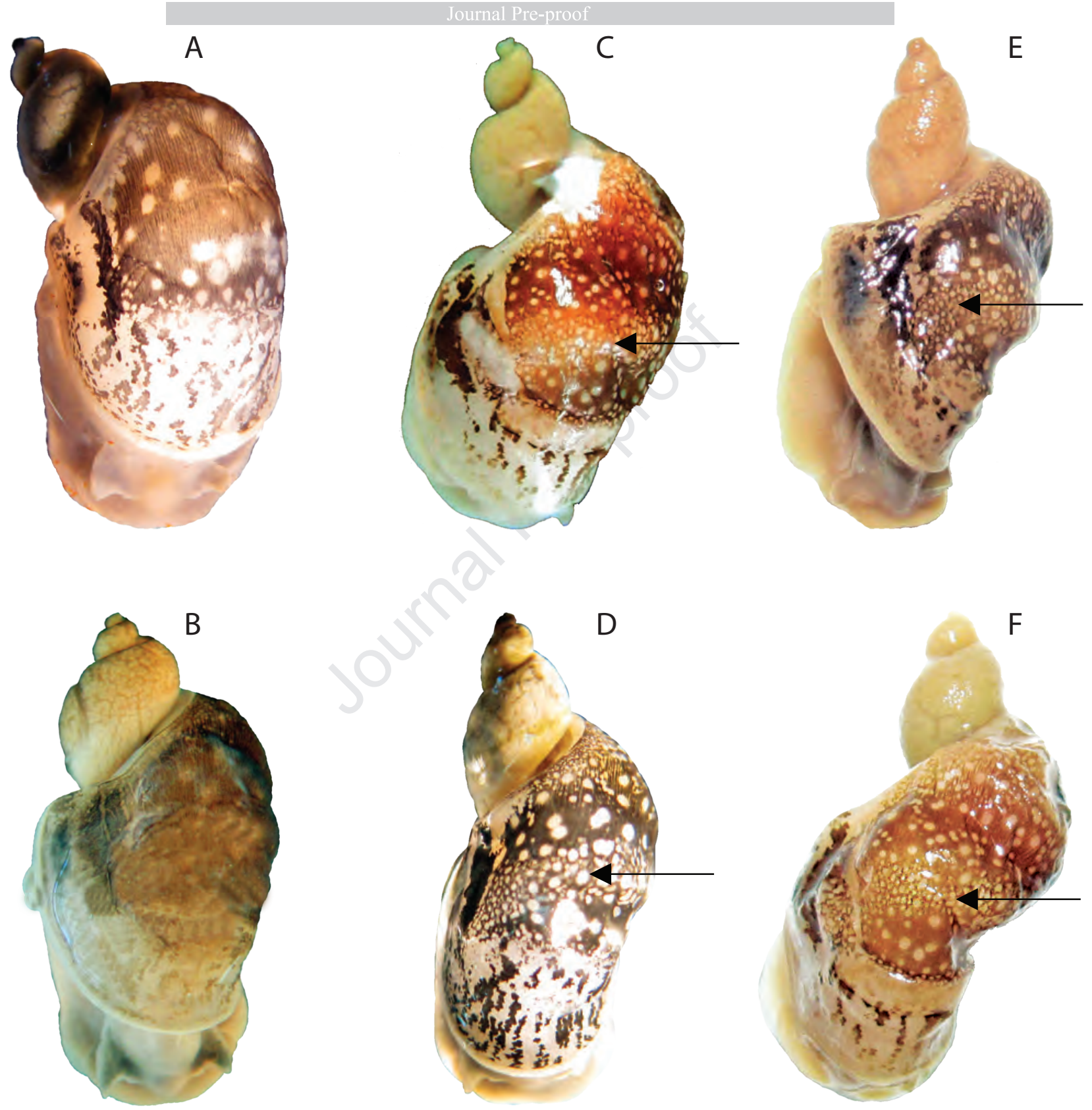
signal transduction in response to DNA... leukocyte adhesion to vascular.. leukocyte tethering or rolling DNA damage response, signal.. cellular extravasation

cell response to DNA damage stimulus cellular response to stimulus cellular response to stress defense response immune response

posit. regulation of response to stimulus regulation of programmed cell death response to chemical response to external stimulus response to stimulus

DNA biosynthetic process DNA conformation change DNA duplex unwinding DNA geometric change DNA metabolic process DNA repair RNA-dependent DNA biosynthesis telomere maintenance telomere organization

neg. regulation multi-organism process anatomical structure homeostasis apoptotic process biological regulation homeostatic process programmed cell death regulation of apoptotic process regulation of biological quality regulation of cell death regulation of multi-organism process regulation of symbiosis, encompassing..

cell surface receptor signaling pathway enzyme linked receptor protein signaling

I-kappaB kinase/NF-kappaB signaling peptidyl-tyrosine dephosphorylation protein dephosphorylation regulation of I-kB kinase/NF-kB signaling signal transduction by $\mathrm{p} 53$ class mediator

amide biosynthetic process cellular amide metabolic process cellular biosynthetic process cellular macromolecule biosynthesis cellular nitrogen compound biosynthesis macromolecule biosynthetic process macromolecule metabolic process organic substance biosynthetic process organic substance metabolic process peptide biosynthetic process peptide metabolic process translation
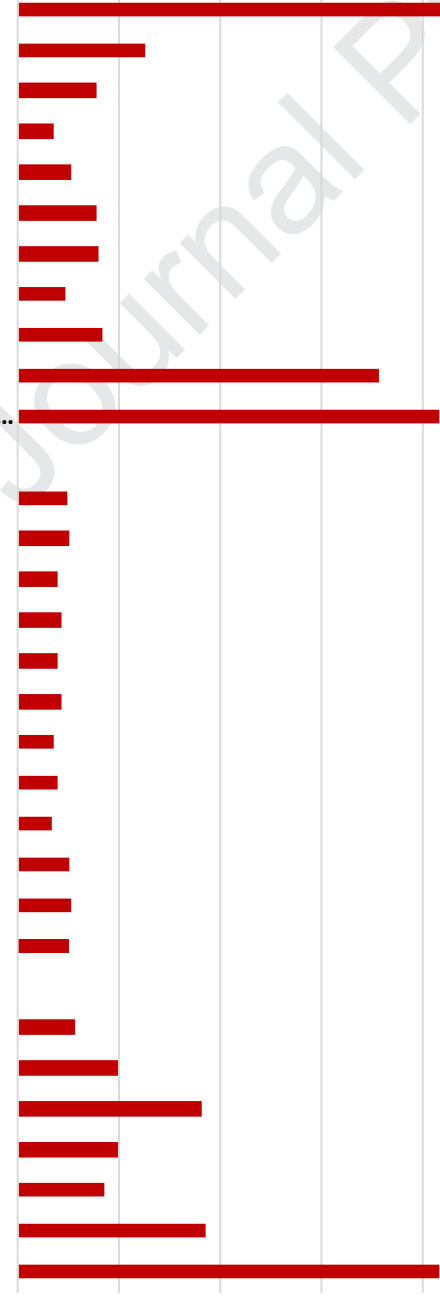

0

40

60

80

Sequences Test data/Reference Data (\%)
B)

calcium ion binding cation binding

DNA helicase activity

DNA polymerase activity

endonuclease activity

endopeptidase activity

G-protein coupled receptor activity helicase activity

hydrolase activity

hydrolase activity, acting on acid...

hydrolase activity, acting on acid...

hydrolase activity, acting on ester... metal ion binding

metalloendopeptidase activity metallopeptidase activity

molecular transducer activity nucleoside-triphosphatase activity peptidase activity, acting on L-... phosphoprotein phosphatase...

protein tyrosine phosphatase

pyrophosphatase activity receptor activity

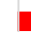

RNA-directed DNA polyme rase... signaling receptor activity structural constituent of ribosome structural molecule activity transmembrane receptor activity transmembrane signaling...

Sequences Test data/Reference Data (\%)

C)

\section{Biological process}

amide biosynthetic process

cellular amide metabolic process

cellular macromolecule...

cellular nitrogen compound...

macromolecule biosynthetic...

peptide biosynthetic process

peptide metabolic process

ribonucleoprotein complex...

ribosome biogenesis

translation

\section{Molecular functions}

structural molecule activity

structural constituent of ribosome 
A)

A2M 1 isoform X2

$\operatorname{annexin} A 3$

antimicrobial peptide...

BPI-like

B-cell receptor CD22-like

CD109 antigen-like

CD209 antigen

CD40 ligand

CD63 antigen

C-type lectin

SAMHD1

ferritin

galactose-specific lectin ... galectin-related precursor

Glutathione S-Transferase

heat shock

heat shock 70

heat-shock Hsp20

leukocyte elastase inhibitor-...

LRR receptor-like Ser/Thr...

lymphocyte antigen 6E-like

macrophage-expressed...

mannose-binding $\mathrm{C}$ -

PECAM-like isoform X2

PTAFR-like

serine-rich adhesin for...

TGF-beta-induced ig-h3-like

TLR 4

TNF superfamily member

transmembrane protease...

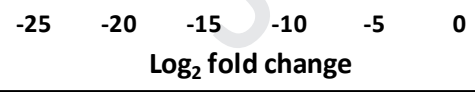

C) acid-sensing ion channel

carbonic anhydrase

membrane antiporter

multisubun it potassium

proton subunit

sodium hydrogen exchanger 10-like

$\mathrm{Na}+/ \mathrm{K}+/ \mathrm{Ca} 2+$ exchanger

$\mathrm{Na}+/ \mathrm{K}+$ transporting ATPase subunit alpha-like

$\mathrm{Na}+/ \mathrm{H}+$ antiporter

$\mathrm{Na}+/ \mathrm{H}+$ exchanger

urea proton symporter DUR3like

V-type proton ATPase
B)

ankyrin repeat and IBR domain

antimicrobial peptide hydramacin baculoviral IAP repeat-containing 3 $B$-cell receptor CD22 isoform X1 BANK cathepsin L1-like catalase CD109 antigen CD209 antigen CD40 lig and-like

C-type lectin

C-type mannose receptor 2 SAMHD1 ferritin

Fibrinogen $\mathrm{C}$ domain-containing 1 fibrinogen-related

G- coupled receptor $M$ th-like galactose-specific lectin nattectin-like galactoside-binding lectin galectin-4 G-CSFR heat shock 70kDa heat shock factor 5 -like Heat shock factor HSF8 hemagglutinin amebocyte aggregation.. IRF

IFN-induced transmembrane Ig I-set domain

Ig-like V-type domain-containing FAM187A

IL enhancer-bin ding factor 3-like isoform X9 interference hedgehog-like kelch 6

killer cell Ig-like receptor 2DL3

killer cell lectin-like receptor subfamily F... leukocyte elastase inhibitor-like LRR LRR-containing LRR soc-2-like

L-type lectin-domain containing receptor.. lymphocyte antigen 75 macrophage mannose receptor 1-like mannose-binding C-like Mannose-binding lectin MIF
Myd88-like
MZB1 MZB1

nitric oxide synthase pathogenesis-related 1-like peptidoglycan binding domain-containing PKC theta type-like probable ATP-dependent RNA helicase... probable deferrochelatase peroxidase probable disease resistance At5g66900... probable LRR receptor kinase proline-rich transmem brane 1-like Ras-like GTP-binding Rho 1 rho-associated kinase 1

SAM domain and HD domain-contain ing 1 scavenger receptor class $\mathrm{F}$ member 1 Soma ferritin SPOR domain-containing Superoxide dismutase $T$ cell receptor

T-cell receptor alpha chain variable TGF-beta-1-like

TGF-beta-in duced ig-h3-like

TLR 3

TLR 4

TLR 8

TNF receptor superfamily member toll

tripartite motif-containing $\mathbf{5 9}$ ubiA prenyltransferase domain-containing... 


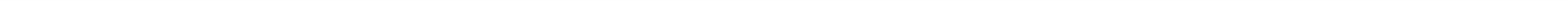




\section{Highlights}

- Comparative "omic" analyses of $P$. columella offer clues for resistance to $F$. hepatica

- Naïve resistant snails display a higher molecular competence for defense/stress responses

- Constitutively broad expression of immune factors associates with resistance to $F$. hepatica

- Overrepresented $\mathrm{pH} /$ osmotic regulators endorse the $\mathrm{pH}$ tolerance of resistant snails

- Resource allocation to defense/stress response endorse reproductive trade-offs 